\title{
IOCA SERIAQUE \\ la faz del poeta y la cruz del racionero en los estribillos de Góngora (1581-1583)
}

\author{
JuAN J. MARTÍNEZ García \\ Universidad de Málaga
}

Corre el año de 1580 y un romance, «Hermana Marica»1 («algo nuevo, que no se ajusta, ni bien ni mal, a los rancios encasillamientos habituales»)2, resuena en la judería de Córdoba. Aún no repuesto de la salva popular, el joven Góngora $^{3}$ vuelve a leer unas coplillas de pie quebrado de don Diego Hurtado

${ }^{1}$ № 4. Las letrillas se numeran según la edición de R. Jammes (Letrillas, Castalia, Madrid, 1980; edición crítica en francés en Ediciones Hispanoamericanas, París, 1963). Los romances y otras composiciones se ordenan siguiendo la edición de A. Carreira (Luis de Góngora. Obras Completas, I, Fundación José A. de Castro, Madrid, 2000. En adelante, OC). El presente artículo reproduce, con ligeras modificaciones, el que aparece en mi tesis doctoral, Iconos de la voz poética en las letrillas burlescas de Góngora, Universidad de Málaga, 2015, págs. 233-264.

2 A. Carreira, «Registros musicales en el romancero de Góngora», en J. Roses (ed.), Góngora hoy, I-III, Diputación de Córdoba, 2002, págs. 73-91; reimpreso en Gongoremas, Península, Barcelona, 1998, 373-414, págs. 379. La opinión de Carreira muestra acertadamente el grato desasosiego que produjo - como el poeta reconoce en su romance «Hanme dicho, hermanas» $(O C, 65)$, de 1587- tal oficio de propósitos, tan contrario a la expresión de ese sentimiento «encasillado» $\mathrm{y}$ «rancio» que degrada al personaje.

${ }^{3}$ El período 1581-1583 corresponde a los primeros años de la estancia de Góngora en el cabildo cordobés, después de sus estudios en Salamanca y mucho antes del viaje a Castilla y a la corte madrileña (1591-1596). Las letrillas fechadas en esta etapa (núms. VII, VIII, XXIV, XXV) poseen estribillos jocoserios en distinta medida. No se incluyen los romances 2, 3, 4, 10, 26 y 38 porque sus estribillos no se ajustan al binarismo de burlas y veras. Por otra parte, los estribillos 
de Mendoza que había apuntado no mucho antes en su codice excerptorii ${ }^{4} \mathrm{y}$ cuya primera estrofa comienza:

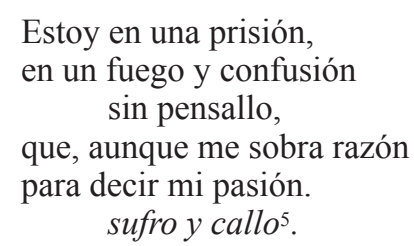

El mismo estribillo aparece en las once estrofas que, como píldoras, sirven de analgesia al canto desesperado del poeta, enredado en la ley vieja de Amor ${ }^{6}$. Más que la sujeción a las convenciones del tópico ${ }^{7}$, al poeta le conmueve el elegante concierto entre la turbación expresada en el primer dístico y la reflexión acogida en el quebrado.

de las letrillas de Góngora ya atrajeron el interés de Gracián. En el Disc. XXVI («De la agudeza Crítica, y Maliciosa») de su Agudeza y Arte de ingenio (Juan Nogués, Huesca, 1648) afirma, ilustrando con la tercera estrofa de la letrilla VII («Que la viuda en el sermón/dé mil suspiros sin son/bien puede ser»), que «todo el artificio desta agudeza consiste en descubrirle la malicia artificiosa al que obra, y sabérsela ponderar» (cursiva mía). Gracián supo medir el alcance de la estimativa en el flujo de una corriente burlesca innovadora, lo que se aprecia en que el ejemplo no aparece en el discurso XIX («De las Crysis Maliciosas») del Arte de Ingenio. Tratado de la Agudeza (Juan Sánchez, Madrid, 1642). A. García Berrio ha clasificado las letrillas de Góngora atendiendo a los aspectos funcionales de los estribillos («Las letrillas de Góngora [estructura pragmática y liricidad del género]», Edad de oro, II, 1983, págs. 89-97). Por su parte, A. Morel D’Arleux («El lugar común y sus aspectos paremiológicos en los estribillos de las letrillas de Góngora», Pandora: revue d'etudes hispaniques, 1, 2001, págs. 69-82) ha distinguido el estribillo propio y la frase proverbial. Véase también R. Jammes, «La letrilla dialogada», en AA. VV., El teatro menor en España a partir del siglo XVI, Madrid, 1983, págs. 91-120.

${ }^{4}$ Cartapacio personal donde se memorizaban «aquellas frases o párrafos que les gustaba, que les parecían relevantes o en los que habrían visto cifrados una idea, un exemplum, un motivo atractivo, una figura de estilo que consideraban dignos de imitación» (L. Schwartz, «Góngora, Quevedo y los clásicos antiguos», en J. Roses (ed.), Góngora hoy, vI: Góngora y sus contemporáneos: de Cervantes a Quevedo, Diputación de Córdoba, 2004, 89-132, pág. 98).

${ }_{5}$ Redondillas de pie quebrado. Estando preso por una pendencia que tuvo en Palacio (Poesía completa, ed de J. I. Díez Fernández, Planeta, Barcelona, n. CXXXV).

${ }^{6}$ «La definición de Amor/según el Ovidio advierte/es ser una dulce muerte/y una vida con dolor./un acuerdo y un olvido/dize, y un mundo al revés, /que haze no ser lo que es:/y ser lo que nunca ha sido» (Cancionero de López Maldonado, Guillermo Droy, Madrid, 1586, s. fol.). Góngora lo expresa bien en la primera estrofa de la letrilla XXV: «En la ley vieja de Amor,/a tantas fojas se halla/que el que más sufre y más calla,/ése librará mejor».

${ }^{7}$ El tópico es constante en la poesía cancioneril quinientista, como se aprecia en el mote ajeno «Esfuerço a sufrir», que glosa Juan del Encina (Obra completa, no 92, Fundación José A. de Castro, Madrid, 1996) y cuya cabeza expresa con resolución un sentimiento reconducido en prejuicio amoroso: «Por más mi mal encubrir/callo y sufro mi penar/y mi forçoso callar/me pone esfuerço a sufrir» (cf. 91 y 93). Por su parte, Hurtado de Mendoza es perseverante en el motivo, génesis de su Canción LXXV («Oigo veo, sufro y callo», v. 13) y de la Carta «a su dama estando ausente» («Yo que sufro, callo y veo», LXIX, v. 109). 
A pesar de que el villancico recuerda los tradicionales cosantes y algunas canciones sin cabeza o sin mote a los que tan aficionado era algún antepasado de don Diego ${ }^{8}$, el tratamiento habitual de la desesperación de amor se manifiesta en unas redondillas del mismo autor bajo la forma medieval de la pregunta:

Amor me manda escribir, temor me fuerza a callar. ¿Qué medio podré hallar seguro para vivir??

La interpelación es una receta ya envejecida y no puede tomarse en serio. Los nuevos tiempos - vino nuevo en odres nuevos- exigen la desmitificación paródica ${ }^{10}$ de la tradición clásica, pero el joven poeta, recordando la Carta de don Diego ${ }^{11}$, prefiere responder con la consideración que le merece:

H. M. Amor me manda escribir, temor me fuerza a callar...,

G. (Eso) es la historia de la fatiga ${ }^{12}$.

Góngora reconoce el desaliento que le produce «Amor a don Diego» (el motivo extensional) y su respuesta se viste de aserción. Aunque no hay diálogo (no están presentes ambos), sí hay dialogismo, y es el predicado de la aserción

${ }^{8}$ Desprende cierto aire de familia el cosaute del antepasado homónimo de don Diego, el Viejo (1364-1404), padre de Don Iñigo López de Mendoza, Marqués de Santillana: «Aquel árbol que buelbe la foxa/algo se le antoxa» (Cancionero de Palacio, ed. de A. Ma Álvarez Pellitero, Junta de Castilla y León, Salamanca, 1993, pág. 16).

${ }_{9}^{9}$ Carta en redondillas, XCIX, vv. 1-4.

${ }^{10}$ Asegura J. Ponce Cárdenas que «las formas y temas que el renacimiento había legado a sus jóvenes herederos, aquel grupo de poetas agrupados generacionalmente en torno a 1560 , fueron pronto sometidos a cambios, fracturas, que oscilaban entre la estilización y la parodia» (Góngora y la poesía culta del siglo XVII, Laberinto, Madrid, 2001, pág. 39).

${ }^{11}$ Es indudable que las canciones y villancicos de Hurtado de Mendoza gozan de estima literaria. «¿Qué cosa iguala a una redondilla de Garci Sánchez o don Diego de Mendoza», pregunta Lope de Vega en el prólogo del Isidro. El aprecio de Góngora no se reduce a la letrilla. El romance «Triste pisa, y afligido» (OC, 63), de 1587, comienza de manera semejante a la Carta en redondillas LXVI: «Triste y áspera fortuna/un preso tiene afligido/mas no por eso vencido/con la fuerza ninguna». La prioridad del adjetivo triste ya aparece en el Cancionero de Palacio (CCXXXIX y CCCXLVI, págs. 226 y 357), pero Góngora tensiona en un solo verso - sinonimia especular - la «historia del triste», de manera semejante a lo que ocurre con «Manda Amor en su fatiga».

${ }^{12}$ Es Góngora (y no sólo el yo poético) quien responde al conflicto expresado en los versos de Hurtado de Mendoza. «Historia de la fatiga» es la expresión predicativa de un motivo general, sin textura. 
gongorina el que expresa el motivo extensional suscrito ${ }^{13}$ en el deíctico oculto, que aquí hago explícito con el demostrativo «eso».

Bien es cierto que juega con ventaja. La voz lírica de don Diego, «Ya no pudiendo sufrir/dolor de tanta fatiga» (Carta en redondillas, LXXII, vv. 281-2), le ofrece la textura poética adecuada al motivo extensional:

Salga, pues Amor lo quiere,

la historia de mi fatiga, y por do quiera que fuere todas mis pasiones diga a quien oírlas quisiere ${ }^{14}$;

\section{1. «Si lo dizen, digan, alma mía» ${ }^{15}$}

Esta primera fase del proceso de suscripción se completa con una segunda etapa donde Góngora provee de textura poética al motivo (o al tópico). En un primer momento de esta fase es el poeta quien opera la reducción del período dialógico — pero también polifónico ${ }^{16}$ - a la simple frase monofónica ${ }^{17}$ para, seguidamente, merodear con su modus predicativo de racionero ${ }^{18}$ en esa parte ya reducida del verso. Y, como se ve, le imprime carácter (letrilla XXV, de 1583 , v. 1):

\section{Manda Amor en su fatiga ${ }^{19}$}

${ }^{13} \mathrm{El}$ «signo de suscripción» concierne al nivel externo de la enunciación, y manifiesta el compromiso de Góngora con el acto de habla de la autoridad poética. La frasis de dicho signo podría ser «suscribo-que $p$ » o «digo-que $p$ es así». Se corresponde con el «neústico» de R. M. Hare (The Language of Moral, Universidad de Oxford, 1952; traducción al español de G. R. Carrió y E. A. Rabossi, El lenguaje de la Moral, unAM, 1975, págs. 27-28). Por otro lado, «motivo extensional» describe una sucesión lineal (por histórica) de frases ficcionales, de leitmotivs de distinto grado que forman una unidad con sentido.

${ }^{14}$ Quintillas a la desesperación de su amor, CXXXIII, vv. 1-5 (cursiva mía). No sabemos si Góngora y su círculo reconocían en este poema a don Diego Hurtado de Mendoza, pero sorprende que seis de sus redondillas y quintillas más cercanas a la invención poética de Góngora, las dedicadas a los pesares y cuidados le sean atribuidas en escasas ocasiones (CXII, CXIII, CXIV), o solo en una sólo (CXXXIV, CXXXV, CXLI).

${ }^{15}$ Cancionero Musical de Palacio, ed. de J. González Cuenca, Visor, Madrid, 1996, no 193. El motivo se reifica en la factualidad de la paradoja: «Quiero callar mi pasión,/quiero encubrir mi tormento, / pues mi triste pensamiento/m' ha puesto en confusión» (loc. cit., no. 169, vv. 18-24).

${ }^{16}$ Con independencia de que se consideren citas de palabras o de pensamiento.

${ }_{17}$ Es una técnica retórica de deflación categorial basada en el topos «menos es más». Permite que una proposición se abrevie en una frase o sintagma para que la voz de la tradición deje de escucharse y el verso acoja sólo la del poeta.

${ }_{18}$ En un primer momento de esta segunda fase se elabora retóricamente la textura, pero el modus con que el poeta unge esta parte del verso es fundamentalmente poético.

19 A. Pérez Lasheras lo expresa de forma parecida. Piensa que la letrilla «es, desde este punto de vista de la separación entre yo poético y yo vital, de gran importancia, dado que en 
El verso es ahora una figura, un icono con dos partes bien diferenciadas. A la izquierda (o antes), el poeta asume directamente la escena emblemática donde Amor hace lo que suele: imponer su propia ley. A la derecha (o después) se encuentra la parte del verso donde el poeta responde a dicha ley con «su» modus. Son dos hemistiquios que mantienen el dialogismo original con los dos tonos de una misma voz. El «mi» de la quintilla de Hurtado de Mendoza («mi fatiga») designa los pesares del yo poético, pero el «su» del hemistiquio de Góngora - que denomino «hemistiquio de autor» ${ }^{20}$ - se liga directamente con Amor y sus palabras, una forma de asumir directamente el emblema. A causa de ello, el anafórico «su» tiene como contenido no tanto los cuidados, pesares o desdichas del poeta (expresados en las cinco sílabas del «hemistiquio de autor») cuanto las proposiciones de cita en estilo indirecto no explícitas, pero mandadas por Amor.

En su momento lo intenta Pedro de Padilla en el cabo de una redondilla ${ }^{21}$ :

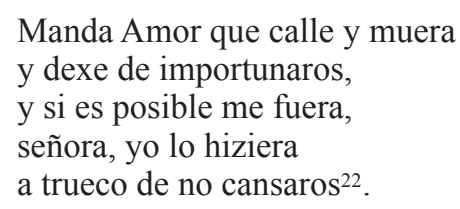

Aquí el poeta destina los tres primeros octosílabos a rubricar la «historia de la fatiga». Es un espacio dilatado, poco propicio a la segunda fase de suscripción del tópico, aunque el de Linares sólo pretende darle la vuelta a lo irónico en la parte final de la redondilla. El ajuste en la argumentación, por lo tanto, se percibe ya en los primeros versos, y es este mismo logos el que aprueba que Amor (una vez tratado con el tono irónico de Padilla) siga haciendo de las suyas.

En unas Estancias en diálogo que son relevantes para este asunto, Padilla insiste en la fórmula trillada de suscripción del tópico:

- Pues dime la ocasión de tu fatiga

- Ame mandado amor que no lo diga ${ }^{23}$

ella se expresa tajantemente la proposición estética» («De máscaras y amores. La superación del petrarquismo en las primeras composiciones gongorinas», Tropelías, 2, 1991, págs. 129-143, recogido en Piedras preciosas. Otros aspectos de la poesía de Góngora, Universidad de Granada, 2009, 149-76, pág. 163). Las cursivas son mías.

${ }^{20}$ Un hemistiquio (o un verso) «de autor» posee inflexiones en el tono que designan el modus del autor más allá del yo burlesco.

${ }^{21}$ La redondilla agrupa, siguiendo a J. Díaz Rengifo (Arte poética española [Salamanca, 1522], MEC, Madrid, 1977, págs. XXII-XXVIII), las coplas en octosílabos o hexasílabos de cuatro o cinco versos y con distintos esquemas métricos. Aquí se emplea en ocasiones, contra lo que suele ser usual, para las coplas o glosas de los villancicos o letrillas, o para las canciones «de villa».

${ }^{22}$ Carta en redondillas de un galán que se disculpa con su dama por averle de ser forzoso dezir su pena (Thesoro de varias poesías [1580], ed. de J. J. Labrador Herraiz y R. A. DiFranco, no. 25, Frente de Afirmación Hispanista, A. C., México, 2008, vv. 1-5).

${ }^{23}$ Romance pastoril con un diálogo entre dos pastores (loc. cit., 142, vv. 101-102). 
Aquí el poeta suscribe mediante la retórica del diálogo (luego verba) lo mismo que rubrica Góngora con las operaciones de primer grado (luego res): el motivo extensional, lo que acredita la validez del diálogo como categoría de la «imitación por suscripción». Tanto es así que este período dialogado, a pesar de su metro, puede funcionar como «figura de paso» en el proceso de imitación ${ }^{24}$ que se resuelve en el estribillo gongorino.

No obstante, el diseño retórico de la fórmula imitativa indica que las maneras gongorinas de afiliación a la tradición son mucho más modernas que las del diálogo de Padilla, que expresan la caduca militia amoris mediante la cita-coda «que no lo diga», una técnica frecuente en los cancioneros petrarquistas que se aprecia con claridad en el siguiente villancico de Juan de Estúñiga, presumible asiento de todo este proceso de imitación:

$$
\begin{aligned}
& \text { Mi peligrosa passión } \\
& \text { me castiga } \\
& \text { que se sienta y no se diga. } \\
& \text { Que mi secreta tristura } \\
& \text { con sello de fe sellada } \\
& \text { mas quiere muerte callada } \\
& \text { que publica desventura. } \\
& \text { Consiente mi coraçon } \\
& \text { mi fatiga } \\
& \text { porque sienta y no se diga }
\end{aligned}
$$

El villancico de Estúñiga exhibe gran parte de los aparejos temáticos y retóricos que se adivinan en Hurtado de Mendoza y en Padilla, entre ellos la suscripción verbal del motivo extensional y la expresión reducida de la cita. A tenor de su valioso diseño retórico fue imitado con habilidad en el entresiglo guiado por los Reyes Católicos, como se advierte en la siguiente redondilla del Cancionero Musical de Palacio:

De la dulce mi enemiga nace un mal que al alma yere. Y por más tormento, quiere que se sienta y no se diga ${ }^{26}$.

${ }^{24}$ Prefiero el término imitación, más intuitivo, al de intertextualidad o transducción, que exigen un estatuto previo.

${ }^{25}$ Cancionero General de Hernando del Castillo (Valencia, 1511), ed. facsímil de A. Rodríguez-Moñino, RAE, Madrid, 1958, fol. CXLVI v.

${ }^{26}$ № 217. Véanse el Cancionero musical de Barbieri (Real Academia de Bellas Artes de San Fernando, no 147, 1890, pág. 102) y J. e I. Millé y Giménez, Luis de Góngora. Obras Completas, Aguilar, Madrid, 1932, pág. 1119). Según Pellicer, en sus comentarios al Quijote, parece parodia del petrarquista italiano Serafino d'Aquila (1466-1500): «De la dolce mia enemica/nasce un duol ch'ésser non suole:/e per piu tormento vuole/che si senta e non si dica» (cf. la deficiente traducción de Lope de Vega en el prólogo del Isidro). La popularidad del estribillo se percibe no sólo en el temprano poema gongorino. En el Quijote (II, XXXVIII), la 
El traslado sin recelo del verso en cuestión —incluido el «que» y su anacrusa como parte de la cita ${ }^{27}$ - ocupa todo el espacio métrico del nuevo verso, que se revela ahora como una especie de nombre icónico cuyo marco está limitado por los deícticos ocultos del estilo directo $(: « »)$ y no por el «que». Si se acepta la pausa de verso como un índice más de este estilo, el primer miembro del estribillo gongorino quedaría así (vv. 1-2):

\section{Manda Amor en su fatiga} «que se sienta y no se diga»

El rasgo de iconicidad propio del segundo verso valida la pervivencia de un código amoroso que habla con voz propia, distinta a la del poeta, pero el cordobés lo dispone (no puede ser de otra manera) después del «hemistiquio de autor», destreza que confiere a todo el icono - que incluye el «que», no sólo a la cita-tópico, que no lo incluye- la modulación irónica a que obliga el modus predicativo impreso en el «hemistiquio de autor», que ahora alcanza la segunda cota de rima y, con ella, el imperio de todo el kolon bajo el gobierno consonante de la «-iga» burlesca. Así, la voz lírica se torna irónica en la coda (el «hemistiquio de autor») y anuda el vínculo figural en la rima ${ }^{28}$, lo que autoriza, antes del segundo dístico dedicado en exclusiva a esta función, la derogación de la ley vieja de Amor.

Ya hay una réplica que suscribe el período de dezir ${ }^{29}$ que contiene la «historia de la fatiga» en el modo en que Hurtado de Mendoza la expresa ${ }^{30}$. Esta moderna aserción gongorina contiene ahora una cita «de la fatiga» a la que se puede adjuntar un «predicado de verdad» externo ${ }^{31}$, enunciado por una voz extraña al poeta. Es la porfía con este predicado lo que reclama, en el segundo dístico del estribillo, una respuesta adecuada a esta cuestión externa.

En la Carta en redondillas, esta respuesta gira en torno al trascendente «cómo»: «mas yo, cuitado, que callo, / ¿cómo es posible pasallo/si de emtrambas

Trifaldi, tras escuchar la copla, reconoce que «lo que más me hizo postrar y dar conmigo en el suelo fueron unas coplas que le oí cantar una noche desde una reja», y ratifica poco después la función musical de la copla: «Y deste jaez otras coplitas y estrambotes, que cantados encantan y escritos suspenden. Pues ¿qué cuando se humillan a componer un género de verso que en Candaya se usaba entonces, a quien ellos llamaban seguidilla? Allí era el brincar de las almas, el retozar de la risa, el desasosiego de los cuerpos y finalmente el azogue de todos los sentidos» (cf. M. Querol Gavaldá, La música en la obra de Cervantes, Centro de Estudios Cervantinos, Alcalá de Henares, 2005, 80-82, pág. 80). Por otra parte, el recurso de los comentaristas del Quijote a la conocida copla del Comendador Escrivá: «Ven, muerte tan escondida/que no te sienta conmigo/porqu'el gozo de contigo/no me torne a dar la vida» (Cancionero General..., fol. CXXVIII v) no es inspirador.

${ }^{27}$ Se cancela su función transpositiva.

${ }^{28}$ Rima que aparece tanto en el villancico de Estúñiga como en las estancias de Padilla.

${ }^{29}$ Carta en redondillas, XCIX, vv. 1-2.

${ }^{30}$ Quintillas a la desesperación de su amor, CXXXIII, v. 2.

31 «Manda Amor en su fatiga/"que se sienta y no se diga" (es verdadero)». Tanto en el mundo del poeta como en el del racionero la verdad de la cita es indiscutible. 
cosas muero?»32 o al más tangible «qué»: «¿Qué medio podré hallar/seguro para vivir?» ${ }^{33}$. La respuesta de la poesía cancioneril es siempre la misma: proclamando el «Sepan quantos...»»34, esto es, pregonando que, para seguir viviendo «seguro», el «medio» es publicar lo que «Amor manda escribir», al fin y al cabo «No hay mal que con publicallo/no se acabe, aunque sea fiero» ${ }^{35}$.

Como es de esperar, Góngora abandona viejas filiaciones y se apropia de su estrenada verdad de Amor ocupando, ahora sí, con su propia voz, las sílabas centrales del espacio métrico (v. 3):

pero a mí más me contenta

Es arrogancia lo que muestra el ethos con voz propia del locutor irónico, cuyos labios vuelven el tópico con la pretendida sencillez del «mí más me» ${ }^{36}$. Lo evidente es que el verso es asediado con la muela que designa rígidamente in jocosa ore a Góngora, evitando así la herida del sarcasmo verbal que, sin embargo, aparece un poco más tarde (vv. 21-24):

$$
\begin{aligned}
& \text { mande amor lo que mandare } \\
& \text { que yo pienso muy sin mengua } \\
& \text { dar libertad a mi lengua, } \\
& \text { y a sus leyes una higa. }
\end{aligned}
$$

En esta poesía de ramillete, la vuelta que propone la rima (vuelvo al estribillo) no puede desenvolverse con naturalidad entre las cuadernas del cartapacio. Su destino natural es la plaza pública, donde el ademán y la mueca se aúnan para desnudar la prosodia de lo recto (de lo serio) y vestirla con la risa de lo jocoso o con la carcajada de lo burlesco. Sólo así es posible imaginar

${ }^{32}$ Quintillas al silencio de sus quejas, CXII, vv. 12-15. El humor atrabiliario de Horacio puede deberse a que su hígado secreta más bilis negra de la conveniente: «meum fervens difficili bile tumet iecur» (Odas, ed. de M. Fernández-Galiano y V. Cristóbal, Cátedra, Madrid, 1, XII, 4) o porque una bilis de otro color lo consume a fuego lento: «quam lentis penitus macerer ignibus» (XII, 8). Góngora no está dispuesto a soportar tamaño mal, y avisa al sufridor: «mas ¡triste del amador/que muerto a enemigas manos,/le hallaron los gusanos/secretos en la barriga!» (vv. 8-12).

${ }^{33}$ Carta en redondillas, XCIX, vv. 3-4.

${ }^{34}$ Frase con que comenzaban las promulgaciones medievales de los documentos diplomáticos, pero también algún dezir, como el siguiente de García de Pedraza que, curiosamente, responde a don Diego à la lettre: «Sepan quantos esta carta/vieren que tanto padeçco,/que con voluntad muy farta/de tristeza ensandeçco» (Cancionero de Palacio, no XXII, pág. 20).

${ }^{35}$ Quintillas al silencio de sus quejas, CXII, vv. 11-12.

36 «Parómenon es cuando muchas palabras comienzan por la misma letra» (G. Correas, Arte de la lengua española castellana [1626], Selecciones Gráficas, Madrid, 1954, pág. 220). No sólo la «letra» es la misma, también el ritmo especular del yambo y el dáctilo apoyan la semejanza. 
el gesto de la higa $^{37}$ sin necesidad de que una palabra lo denote ${ }^{38}$. La rima en «-iga» del primer dístico del estribillo funciona como un deíctico apropiado para esta actio $^{39}$ expresada por el poeta, pero figurada por el lector. Aquí se aprecia el sencillo conceptismo de su primera y alegre poesía, cercano a lo que Gracián clasifica como «Agudeza de Acción» ${ }^{40}$, y que también se muestra en la clausura del segundo miembro del estribillo (3-4):

pero a mí más me contenta

que se diga y no se sienta ${ }^{41}$.

El giro retórico de los términos sentimentales comporta necesariamente el giro del tópico - luego el giro de género-- expresados todos ellos en la figura más amplia del quiasmo. El verso de cierre exprime las correspondencias ${ }^{42}$ que antes habían sido mostradas y que ahora son dichas mediante las artes de la parodia. Así, volviendo (literalmente) el segundo verso — reglado según la ley vieja de Amor - del revés, se vuelve (paródicamente) del revés el tópico.

Es moderna la estrategia para que la parodia ${ }^{43}$ se ajuste a la metáfora del

${ }^{37}$ Amuleto de cristal, de ámbar, etc., en forma de mano cerrada en que asoma el dedo pulgar entre el índice y el medio. También el ademán de menosprecio o de burla que lo motiva (cf. R. Jammes, Letrillas, pág. 72). Años más tarde, en 1593, es él mismo quien se despacha la primera higa (letrilla XII): «Un buhonero ha empleado/en higas hoy su caudal,/y aunque no son de cristal/todas las ha despachado;/para mí le he demandado,/cuando verdades no diga, / una higa». Véase la nota final.

${ }^{38} \mathrm{La}$ diferencia se aprecia entre la rima en «iga», de índole intensional, y la «higa» explicitada en el verso 24: «y a sus leyes una higa».

${ }^{39}$ Aquí la rima, además de sus valores fónicos o semánticos, posee una deixis asociada a un sentido. Por otra parte, la actio propuesta no se identifica con la fase retórica homónima sino que se encuentra en la elocución. Es, por lo tanto, una actio elocutiva cuyo desarrollo explico en el apéndice «Del emblema al refrán: la actio en los estribillos de Góngora» de mi tesis doctoral (op. cit., págs. 111-180).

40 Tercer tipo de esa Agudeza compuesta que «consta de muchos actos» (Agudeza..., disc. III). Gracián no la define porque no es cuestión de palabras, sino de ostensión, y así ejemplifica con argumentos evidenciales, como el anillo que deja caer Carlos V en Francia o el famoso tapete de Selim.

${ }^{41}$ «Decir, gritar, no aguantar callando... Esta gana irreverente de hablar, que ya hemos visto proclamada en alguna letrilla satírica, es una de las características de la personalidad de don Luis, y la base de su anticonformismo» (R. Jammes, Letrillas, 1980, pág. 117).

${ }^{42}$ El concepto es «Un acto del entendimiento que exprime la correspondencia que se halla entre los objetos» (B. Gracián, op. cit., disc. II ).

${ }^{43}$ Robert F. Ball sugiere que «la imitación negativa, o parodia, apunta a un modelo falso o exagerado que necesita la reducción materialista del texto paródico» («Imitación y parodia en la poesía de Góngora», en VI Congreso Internacional de Hispanistas, ed. de A. M. Gordon y E. Rugg, Universidad de Toronto, 1980, 90-93, pág. 91). En este estribillo, la descitación paródica no reduce el material (y quizá tampoco el asunto): «this type, closest to the etymological meaning of $\pi \alpha \rho \omega \delta i ́ \alpha$ as a "song against another song" corresponds within the spectrum of negative imitation to the translation within that of positive imitation» (Góngora's Parodies of Literary Convention, Universidad de Yale, Tesis microfilmada, 1976, pág. 273). 
volver: apropiarse de palabras viejas y proveer de efecto de verdad ${ }^{44}$ a las nuevas. Se podría decir que el poeta cita las palabras-tópico que originan el icono conceptual del entrecomillado - tornavoz pertinaz «de la fatiga»- con la única intención de liberarlas de su eco en el verso de cierre mediante la sutileza de la descitación. El sello de suscripción del desentrecomillado es ese «que» del cuarto verso, situado ahora fuera del icono destinado al palimpsesto:

\section{Manda Amor en su fatiga «que se sienta y no se diga», pero a mí más me contenta que se diga y no se sienta.}

Esta «poética de la inversión»(del volver), airosamente engastada en un objeto retórico ${ }^{45}$ tan depurado, denotan que la letrilla de 1583 es el éxito de artificios que deben estar sólo despuntando en poemas anteriores. En el temprano romance con estribillo «Ciego que apuntas y atinas» ${ }^{46}$, de 1580 , se dirige a los «Amadores desdichados / que seguís milicia tal» (vv. 23-23) y que, como ellos, "Gloria llamaba a la pena, /a la cárcel, libertad,/miel dulce al amargo acíbar,/principio al fin bien al mal» (vv. 45-48). Naturalmente, Chacón lo incluye entre los amorosos, sin percibir que el romance alberga la pretensión de «desmantelar una tradición» ${ }^{47}$ mediante la simple deserción, sobre todo después de que «Diez años desperdicié, /los mejores años de mi edad/en ser labrador de amor» (vv. 31-33). A los 19 años, la única militia a la que alistarse es la de Apolo, y así lo dice, literalmente, en estos versos con voz eiron ${ }^{48}$ que rubrica el estribillo: «Déjame en paz, Amor tirano,/déjame en paz», ya sin los mecanismos de suscripción de primer grado que velan la lectura habitual a contemplación ajena de «Manda Amor en su fatiga», y quizá también del resto de letrillas de este período.

Pero también hay términos que apuntan maneras. Ahí están «ciego» (vv. 1, 24), el cultismo «inqüietas» (v. 13) o ese mismo «labrador» (v. 33) que aparecen,

${ }^{44}$ La letrilla «renuncia a la descripción de la verdad vital como fuente poética, instaurando un concepto de verdad poética diferente y mucho más moderno [...]. Así, entre burlas y veras, don Luis está formulando una de las grandes verdades de la poética moderna» (A. Pérez Lasheras y J. M. Micó, Luis de Góngora. Poesía selecta, Taurus, Madrid, 1991, pág. 31).

${ }^{45}$ Cada uno de los dísticos posee su propio «predicado de verdad». El primero asevera con voz ajena el contenido de la cita y el segundo afirma con voz propia su «propia» verdad, poética, pero verdad al fin y al cabo. Estos predicados consolidan una de las vías de la «poética del estribillo» de Góngora.

${ }^{46} O C$, 4. A. Pérez Lasheras cree que «este romance consiste en una parodia de los sonetos-prólogo de los cancioneros petrarquistas» en los que «la parodia de los temas y motivos y, sobre todo, de la actitud del amante petrarquista es manifiesta» («De máscaras...», págs. 167 y sigs.).

${ }^{47}$ J. Ma Micó, De Góngora, Biblioteca Nueva, Madrid, 2001, pág. 48.

48 «Así, habrá pocas declaraciones poéticas más deliberadamente falsa que la de esos "diez años" de trabajos de amor perdidos cuando no se tienen sino dieciocho o diecinueve de edad», piensa Micó (loc. cit., pág. 49). 
todos juntos, en la letrilla escrológica «Si en todo lo qu'hago» (XXVI, de 1585), punto de inflexión en su propuesta poética. Es también posible que estos versos sólo se vuelvan a lo burlesco, pero incluso así, mediante la autoparodia ${ }^{49}$, el romance justifica el carácter irónico que muy pronto Góngora verbaliza en el romance «Noble desengaño» ${ }^{50}$, de 1584 :

$$
\begin{aligned}
& \text { Pero ¿quién se mete } \\
& \text { en cosas de seso, } \\
& \text { y en hablar de veras } \\
& \text { en aquestos tiempos, } \\
& \text { donde el que más trata } \\
& \text { de burlas y juegos, } \\
& \text { ése es quien se viste } \\
& \text { más a lo moderno? }
\end{aligned}
$$

El desapego en la demanda no es cosa nueva, pero no suele escucharse la voz del racionero tan abandonada de su responsabilidad ciudadana, aunque en los tercetos «¡Mal haya en que en señores idolatra...!» (n. 202, de 1609) aparece su credo poético: «contiene la república volante/poetas, o burlescos sean o graves» (vv. 23-24).

La otra voz que se escucha es la del poeta, que se dirige a la dama mediante la habitual apóstrofe burlesca de carácter patético: «Ingrata señora,/de tus aposentos/(más dulce y sabrosa/que nabo en adviento)», para después pedirle que se tranquilice con idéntico ethos vocal: «aplícame un rato/el oído atento $\rangle^{51}$. Hay cierta impostura en el tratamiento de la dama que augura un nuevo tono a partir de estos años centrales de la década, y que se muestra en el romance «Ensíllenme el asno rucio».

\section{2. «En unas mismas plumas escondido»}

En el camino, alguna composición se corresponde con otro momento vital. La letrilla VIII, de 1581, es peregrina en el corpus gongorino a tenor de la poca atención que ha suscitado ${ }^{52}$ :

49 Robert F. Ball distingue tres fases del proceso de imitación y parodia: «Entre 1580 y 1600, Góngora inicia su carrera con la imitación de poetas líricos reconocidos como modelos del petrarquismo - Garcilaso, Bernardo y Torquato Tasso, Ariosto, Sannazaro, Minturnoy con la parodia burlesca de figuras que simbolizan el amor patético o romántico en el repertorio de los romances viejos y nuevos españoles —Durandarte, Belerma y Doña Alda, Gaiferos y Melisendra, el pastor y su ninfa, el moro granadino y su dama, Hero y Leandro-» («Imitación y parodia...», pág. 91).

50 OC 48; vv. 41-48.

${ }^{51}$ Romance «Noble desengaño», de 1584; vv. 49-54. Puntuación chocante de A. Carreira.

52 Hasta el punto que R. Jammes no le encuentra acomodo en ningún apartado de La obra poética de Don Luis de Góngora y Argote (Castalia, Madrid, 1987). 
Da bienes Fortuna

que no están escritos:

cuando pitos, flautas,

cuando flautas, pitos ${ }^{53}$.

Si la deserción de la militia amoris es providencial para el éxito en este primer lustro, una letrilla que dedica su estribillo a entronizar la figura de una diosa pagana - a pesar de que, junto con Amor, sean los motivos principales de la poesía cancioneril- debe encontrar su lugar en el camino vital del racionero y poeta. Emana de ella un cierto estoicismo - los dioses no influyen en los hombres y dejan sus destinos al azar- seguramente filtrado por los denuestos y alabanzas propios del debate medieval en torno al tópico de la volubilidad de la fortuna ${ }^{54}$. Lo relevante aquí es que el lugar común se ofrece con el tono sosegado de la voz lírica ${ }^{55}$, alejado de los excesos de la usual indignatio, que recuerda, por cercano, los juegos infantiles de «Hermana Marica».

El poeta veinteañero parece ausente en el estribillo, proscenio donde se desarrolla el acto. Hasta el momento, el trato con Fortuna suele desarrollarse bajo las formas directas del diálogo ${ }^{56} \mathrm{o}$ del dezir. Góngora no tiene otra opción que acogerse a esta última si quiere huir de la escena: «Como procede fortuna/ mostrando su grand poder,/non sé que en parte ninguna/yo me pudiera esconder» ${ }^{57}$. El caso es que sólo se oculta, pero no huye, y el recurso empleado es ya conocido: se trata de asumir la acción que se desarrolla en el primer verso-escena y suscribirla. Si en la letrilla «de la fatiga» la suscripción ocupa

${ }^{53}$ Se ha apuntado a Juvenal como inspirador de esta letrilla: «multi committunt eadem diuerso crimina fato: ille crucem sceleris pretium tulit, hic diadema» (Sátiras, ed. bilingüe de B. Segura Ramos, XIII, CSIC, Madrid, 1996, 105). Aunque no es Juvenal un autor que profundice en los temas morales, el afecto fuerte (deinosis) expresado en la letrilla se inscribe en el espíritu de unos versos anteriores que recogen el conocido debate entre estoicos y epicúreos: «sunt in fortunae qui casibus omnia ponant/et nullo credant mundum rectore moueri/natura uoluente uices et lucis et anni,/atque ideo intrepidi quaecumque altaria tangunt./ [est alius metuens ne crimen poena sequatur.]/hic putat esse deos et peierat, atque ita secum:/decernat quodcumque uolet de corpore nostro/Isis et irato feriat mea lumina sistro» (Sát., XIII, 86-93).

54 «pero actualizado y transferido a un nivel más humilde y cotidiano [...]. Actitud constante de Góngora, que así consigue dar un alcance moderno y, a veces, subversivo a lo que se había transformado en tópico anodino» (R. Jammes, Letrillas, 1980, pág. 59).

${ }^{55}$ Esta voz tan peculiar también hizo dudar a Chacón, quien la incluyó entre las «Poesías varias» (Obras de don Luis de Góngora [Manuscrito Chacón], ed. facsímil, RAE/Caja de Ahorros de Ronda, Málaga, 1991, pág. 71).

${ }^{56}$ Cuando Francisco Imperial, en requesta contra Fray Alfonso de la Monja, le pregunta «qué cosa es la Fortuna», lo hace bajo las formas del dezir: «Pues que assí destribuyes/en el mundo los tus bienes, /non ordenas, mas destruyes/tan sin razon das e tienes» (Cancionero de Juan Alfonso de Baena, ed. de B. Dutton y J. González Cuenca, no. 245, Visor, Madrid, 1993, vv. 9-12). El enfado se produce «Ca siempre veo que eres/discordante a Natura» (vv. 17-18). Este nuevo estilo de diálogo y debate parece que alcanza mayoría de edad en el Bías contra Fortuna, del Marqués de Santillana.

${ }^{57}$ Johan de Andújar, en el Cancionero de Estúñiga (ed. de N. Salvador Miguel), no XVIII, Alhambra, Madrid, 1987, vv. 1-4. 
un hemistiquio porque el motivo extensional posee textura, aquí no existe tejido que invertir y lo que se suscribe se alarga en su descripción, ocupando todo el segundo verso ${ }^{58}$ :

$$
\begin{aligned}
& \text { Da bienes Fortuna } \\
& \text { que no están escritos, }
\end{aligned}
$$

Un hexasílabo para el reparto de Fortuna y otro para el «verso de autor» parece, ahora sí, un reparto poéticamente justo (por polifónico), semejante a la distribución que en la letrilla «de la fatiga» se produce entre el hemistiquio dedicado a la suscripción del motivo y el «hemistiquio de autor» $»^{59}$, donde se escucha la voz del poeta con el tono del racionero. Por otra parte, no hay en esta letrilla «de la Fortuna» una figura que dice sin hablar («Manda Amor... / que...») o una voz figural que porfía («Di, Fortuna, ¿qué pretendes, / con mi pérdida ganar,/que el mayor contento mío/me le has querido quitar») ${ }^{60}$, sino unas figuras del retablo ${ }^{61}$ que se distribuyen la escena y el coro.

En la primera asoma Fortuna sujeta a la rueda. Es un icono prestigioso de la mentalidad renacentista que no parece tener líneas bien definidas. El emblema $\mathrm{CXXI}^{62}$ de Alciato (In occasionem) localiza la figura sobre una rueda echada en la tierra, pero una tradición medieval tardía la personifica, situándola en el centro de los radios («mulier rotae innexa est fortuna gloriae intexta») ${ }^{63}$ que hace girar con sus propios brazos al tiempo que alza e inclina la cabeza. La figura que aparece en el estribillo-escena puede adoptar el perfil de cualquiera de las dos. Su función es mostrar vía emblema — rota Fortunae-

${ }^{58} \mathrm{Si}$ antes el poeta se guarnecía en un «hemistiquio de autor», ahora necesita un completo «estico» ( $\sigma \tau i ́ \chi 0 \varsigma$, «línea», «verso»). La cursiva es mía.

${ }^{59}$ La letrilla «de la Fortuna» es de 1581, y ya se perciben en ella las técnicas de suscripción que se depuran en la letrilla «de la fatiga», de 1583 (no XXV), donde el hexasílabo inicial se reduce a un hemistiquio de tipo pragmático de cinco sílabas («en su fatiga») en el interior de un octosílabo.

${ }^{60}$ Cancionero autógrafo de Pedro de Padilla (ed. de J. J. Labrador Herraiz y R. A. DiFranco), Frente de Afirmación Hispanista, no. 276, A. C., México, 2007. Este ethos tan tierno con Fortuna dio lugar a un contrahecho a lo divino en el mismo cancionero: «Pues tengo a Dios ofendido, ¿qué me queda que esperar?,/tan justamente padezco/que no me puedo quexar» (no. 113).

${ }^{61}$ La imagen es de I. Arellano (Poesía satírico-burlesca de Quevedo. Estudio y anotación filológica de los sonetos, Iberoamericana/Vervuert, Madrid/Frankfurt, 2003, cap. 1).

${ }^{62}$ Este emblema, con la Fortuna en lo alto de la rueda y moviéndola sin descanso gracias a las alas que tiene en los tobillos, aparece en numerosos exlibris y tipografías del Renacimiento, y da lugar al tópico icónico de la rueda de la Fortuna. El origen de la alegoría se encuentra en el retrato que, según Horacio, Lisipo hizo a Alejandro Magno (Epístolas, 2, 1, 237-41).

${ }^{63}$ Honorio de Autun, Speculum Ecclesiae, Dom. XI, en J. P. Migne, Patrologiae cursus completus: sive Bibliotheca universalis, París, 1882-1902, vol. 172, 807-1107, col. 1103, 221 vols. En Las Trescientas de Juan de Mena la imagen es parecida: «Tus casos falaçes, Fortuna, cantamos, / estados de gentes que giras e trocas, / tus grandes discordias, tus firmezas pocas, /y los que en tu rueda quexosos fallamos» (vv. 9-12). 
su jurisdicción sobre personas y bienes, como el mismo Góngora precisa en el romance «Trepan los gitanos», de 1603:

Gitanos de corte,

que sobre su rueda

les mostró, Fortuna,

a dar muchas vueltas ${ }^{64}$

Lo curioso es que la poesía cancioneril está plagada de bienes considerados propios $^{65}$. Algo parecido sucede con la letra «Un solo bien que tenía/Fortuna me lo desvía», glosada por Pedro de Padilla ${ }^{66}$. Incluso si Fortuna es el tercero en discordia, como sucede en los poemas amorosos, la porfía es inevitable: «Los bienes que a mi me distes / a quien se los days señora?» ${ }^{67}$. Olvidan que lo que ofrece Fortuna, en palabras de Bías, «son bienes a vicendas» ${ }^{68}$ (casuales, temporales) y, como en la tragedia antigua, lo que empieza bien acaba mal. En estos ejemplos, los bienes considerados propios (que se encuentran no sólo en el imaginario del poeta) se sirven de la anacrusa para su articulación mediante demostrativos («estos», «un», «los»).

Góngora, incapaz de porfiar con Fortuna, se retrasa a un segundo espacio - ese segundo verso en que se ubica el coro- y se dirige al oyente con voz mansa, suscribiendo con ethos deliberativo, digno de crédito, lo arbitrario de sus enseñas. Si en la letrilla «de la fatiga» se deroga la ley vieja de Amor con el tono paródico impreso en el «hemistiquio de autor» y la consonante «-iga» burlesca, en esta letrilla anterior es el talante ${ }^{69}$ lo que confiere la auctoritas que permite a la voz del racionero — no tanto del poeta - revocar las leyes viejas de Fortuna con la pericia del «verso de autor». Alejados los diálogos in absentia promovidos para su posterior suscripción - como ocurre en la

${ }^{64}$ №. 153 , vv. $5-9$.

65 «Estos bienes de fortuna/males son muy conocidos,/pues por ello son perdidos/no sólo persona una, / mas los más de los nacidos. / Los sin ellos por ganallos, / los con ellos, por tenellos, /los unos, por alcancallos/los otros por no perdellos/son perdidos ellos y ellos» (Cancionero de Sebastián de Horozco, ed. de J. J. Labrador Herráiz, R. A. DiFranco y R. Morillo-Velarde, Consejería de Educación, Ciencia y Cultura de Castilla la Mancha, Toledo, $2010, n^{\circ}$ 325, con poemas recogidos entre 1546 y 1577). Es glosa de la copla ajena «No es pobre quien poco tiene, mas el que mucho desea».

${ }_{66}$ Cancionero de poesías varias. Manuscrito 1587 de la Biblioteca Real de Madrid (ed. de J. Labrador y R. S. Di Franco), Visor, Madrid, 1994, núms. 107 y 108.

${ }^{67}$ Cancionero de López Maldonado, fol. 39v.

68 Bías contra Fortuna (Marqués de Santillana, Poesías completas, II, ed. de M. Durán, Castalia, Madrid, 1980, v. 727). Bías era hermano de Melampo, uno de los Siete Sabios de Grecia.

${ }^{69} \mathrm{El}$ talante (ethos) es uno de los recursos de la persuasión (písteis). Si el talante del poeta lo reputa como persona digna de crédito antes, incluso, de la lectura poética, hablamos de auctoritas (Cicerón, Sobre el orador, trad. de J. J. Iso, II, Gredos, Madrid, 2002, 43; véase Platón, Gorgias, en Diálogos, trad. y notas de J. Calonge, II, Gredos, Madrid, págs. 9-145, 513b-c). Góngora tiene 20 años, y debe conseguir la autoridad con las técnicas propias del discurso, como defiende Aristóteles (Retórica, trad. de Q. Racionero, Gredos, Madrid, 1990, 1356a). 
letrilla «de la fatiga»— la función primaria del «verso de autor» se reduce aquí a la simple asunción de la figura expuesta en la escena.

$\mathrm{Y}$ es el racionero quien la asume sustituyendo la rueda por la pluma soberana («que no están escritos»), más vivencial70 a pesar de la ausencia del locativo. Junto a Fortuna, el autor aposta un objeto insólito en la escena-tópico, unas páginas donde se encuentran escritos los bienes particulares que Fortuna se encarga de adjudicar a su manera. También es posible que no aparezca dicho objeto en el proscenio y Góngora lo sitúe fuera de él. En ambos casos, tanto si está dentro de la escena de esa manera como fuera de ella, es Góngora quien asume el objeto en la autoridad de la sintaxis del «verso de autor», que exige - como ocurría en la letrilla «de la fatiga»- un nuevo «predicado de verdad», esta vez sobre la vivencia del racionero. Si esto es así, el tópico de Fortuna no parece el asunto de este par de versos; hay que buscar una vivencia de fortuna en el mundo del autor.

Esta clase de enseñanza suele encontrar acomodo en la poesía moral. Diego de San Pedro sugiere en la Invocación de su Desprecio de Fortuna que «no es pobre quien poco tiene/mas el que mucho desea» ${ }^{71}$, pero la voz cansada del tópico aparece en el «mote ageno», recogido en el Cancionero de López Maldonado, «Yo é hecho lo que he podido, / fortuna lo que ha querido»72. No sabemos si Góngora es objeto apropiado de la Invocación, pero parece que asume el mote a lo jocoso (vv. 3-4):

cuando pitos, flautas,

cuando flautas, pitos $^{73}$.

Fortuna ha ocupado el proscenio y en el coro sólo se oye la voz del autor. A partir de ahora, todo el espacio métrico (igual que en la letrilla «de la fatiga») se destina a la amplificación paródica de la voz que preside el segundo verso, que carece de las suscripciones necesarias para la derogación del tópico. Aunque todavía está lejos de la poética de la citación-descitación ${ }^{74}$ (con las artes del entrecomillado y desentrecomillado de palabras), este par de versos muestra bien el origen de la fórmula. Si se mantiene la propuesta de lectura, en el paradigma «pitos-flautas» hay zeugma de «escribir» y en el posterior («flautas-pitos») de «dar», única manera de que Fortuna reciba los bienes al modo de Góngora: antes de repartirlos. En el camino, la flexión de número

${ }^{70}$ Para un análisis pragmático de la vivencialidad, véase mi artículo «La geografía burlesca de Góngora, I. Loci vivenciales y no vivenciales en la letrilla VII», AnMal, XXXVII, 1-2, 2014, págs. 83-131.

${ }^{71}$ Estos versos imitan el conocido aforismo de Séneca «Pobre no es el que tiene poco, sino el que mucho desea» (Cartas a Lucilio, VII, XLVII).

${ }^{72}$ Op. cit., fol. $34 \mathrm{v}$.

${ }^{73}$ Este segundo miembro asoma en Correas, pero no parece haberse empleado antes de Góngora.

${ }^{74}$ En mi tesis doctoral (op. cit.) he aclarado el rigor de esta poética de la citación y su correlato retórico del entrecomillado también a partir de 1585. 
abandona la designación del bien escrito en las páginas para denotar lo bueno o lo malo de sus particulares. El esqueleto de ambos versos se encarna así:

cuando está escrito el bien «pitos», Fortuna da flautas, cuando está escrito el bien «flautas», Fortuna da pitos.

Es la primera vez que aparece el desentrecomillado directo de palabras escritas, destreza que encuentra su culminación en la descitación de palabras dichas de la «letrilla de la fatiga». Este salto desde la escena que se muestra hasta el icono verbal que parodia el decir debe su éxito a la progresiva depuración del ethos gongorino, tímido al principio, maduro y arrogante poco más tarde. La deuda que liquida durante estos primeros tres años de la década es la deuda moral que el racionero ha contraído durante los felices años de estancia universitaria en Salamanca ${ }^{75}$. En pago por su natural7 ${ }^{76}$, por sus agudezas inauditas, la familia lo destina «desde muy joven a ser el heredero de las prebendas de su tío, Francisco de Góngora» ${ }^{77}$, en tanto que el hermano menor, don Juan, hereda los bienes civiles de la familia, las tierras y las rentas, en una especie de «mayorazgo inalienable del hermano menor» ${ }^{78}$. A los veinte años, es tarde para cambiar una

75 Pellicer de Salas y Tovar aclara: «assi no me marauillo que no se diesse del todo a la atencion de los Derechos, que era la facultad a que le inclinauan sus padres; porque, obedeciendo a su natural, se dexo arrastrar dulçemente de lo sabroso de la erudiçion y de lo festiuo de las Musas» (en Obras poéticas de D. Luis de Góngora, III, ed. de Foulché-Delbosc, Hispanic Society of America, Nueva York, 1921, pág. 298). «Esperaba sin duda, don Francisco de Argote que al regresar su hijo de Salamanca, volvería graduado y dispuesto a solicitar y ejercer empleo que le diese honra y provecho. Don Luis tuvo que confesar la verdad, y la verdad debió producir honda tristeza al padre, que tantas esperanzas había puesto en el ingenio del hijo» (M. Artigas, Don Luis de Góngora y Argote. Biografía y estudio crítico, RAE, Madrid, 1925, pág. 38).

76 «QQué gran ingenio tienes, muchacho!», le reconoce Ambrosio de Morales (M. Artigas, loc. cit., pág. 26). Sorprende que tanto ingenio no fuese mérito suficiente para el mayorazgo. M. Artigas documenta que don Luis llega a estar desahuciado por una grave lesión a resultas de la caída por una barbacana de la muralla de Córdoba, por lo que «consideraciones pseudocientíficas nonnatas vendrían a querer demostrar que el Polifemo y las Soledades se incubaron en aquella tremenda conmoción que el débil cerebro del infante sufrió en la caída de la Huerta del Rey» (loc. cit., págs. 24-5).

${ }^{77}$ R. Jammes, La obra poética..., pág. 4. Con sólo catorce años, en 1575, ya es «clérigo» (loc. cit.) y sin duda el tío racionero, don Francisco de Góngora, tiene mucho que ver en esta decisión temprana de cuyas consecuencias no es consciente don Luis en estos momentos. En 1582, entre las letrillas «de Fortuna» y «de la fatiga», don Francisco redacta su testamento, confirmando el mayorazgo para don Juan, el hermano menor, y don Luis se ve obligado proceder «a la designación de un titular de este mayorazgo» (loc. cit., pág. 6).

${ }_{78}$ R. Jammes, loc. cit., pág. 17. En el soneto «Io pur travaglio», de Serafino Aquilano, hay unos versos («Nascon doi legni in un medesimo loco, / E de l'un fassi un dio vago \& ornato; / Ch ognum l'adora: e l'altro e sol dicato/ Ad esser forche: o destinato al foco») que, traducidos por Andrés Rey de Artieda de esta manera tan personal: «De un mismo tronco salen; / el uno cual deidad es adorado, / el otro es de los cielos destinado/para que a un triste malhechor empalen» (Discursos, epistolas y epigrama de Artemidoro..., Zaragoza, 1605, fol. 101r), recuerdan la 
vida de segundón ${ }^{79}$ concebida para pasear por las estrechas calles de una ciudad con unos pocos miles habitantes ${ }^{80}$, y la voz protesta de que otros han escrito ${ }^{81}$ un destino que ahora, piensa, no le pertenece, pero no puede lamentarse con la retórica de la queja: «Amor, fortuna y ventura/son enemigos de mí./¡Ved en qué dicha nací! $\rangle^{82}$.

$\mathrm{Su}$ ventura se adornaba con el caduceo de Mercurio, dios de las artes, y con las cornucopias que Fortuna concede a los elocuentes (Virtute Fortuna comes) s3 $^{83}$ ya que el arte, el mérito personal, es capaz de imponerse a las menguas de la Fortuna enemiga (Ars naturam adiuvans) ${ }^{84} \mathrm{y}$-Audaces fortuna iuvat ${ }^{85}$ someterla. Como sugiere Pellicer de Salas y Tovar, en cita que autoriza la función extensional del estribillo, Góngora labra su destino «descogiendo entre la medianía de los bienes de Fortuna la excelencia de los de naturaleza que poseía ${ }^{86}$.

última copla de la letrilla gongorina: «Porque en una aldea/un pobre mancebo/hurtó sólo un huevo,/al sol bambolea;/y otro se pasea/con cien mil delitos».

79 «En la ciudad de Córdoba dan este nombre al hijo segundo de los caballeros principales» (Aut.). Hay un eco en Las firmezas de Isabela: «que lo segundo no quiero» (v. 1529).

${ }^{80}$ Valga este brevísimo apunte biográfico para entender que muchos lectores u oyentes incluyen una creencia en el ínterin de la transmisión, es decir, interpretan de re la letrilla. Tal creencia individual incluye al hijo de don Francisco de Argote en la letrilla antes de su recepción. P. Ruiz Pérez opina, por el contrario, que «si tal entidad [la identidad como entidad cerrada y definida] existe en el individuo Góngora, el poeta se empeña en soterrarla, en dejarla al margen de la construcción lírica, situando ésta en una relación de absoluta autonomía con la personalidad autorial» (La rúbrica del poeta. La expresión de la autoconciencia poética de Boscán a Góngora, Universidad de Valladolid, 2009, pág. 239).

81 Adolfo de Castro afirma, en referencia al segundo verso de la primera redondilla («iCuán diversas sendas/se suelen seguir/en el repartir/honras y haciendas!»), que «en un error gramatical de semejante clase no pudo haber incurrido Don Luis. Debe escribirse el verso: suele seguir, haciendo diéresis» (Poetas líricos de los siglos XVI y XVII, Rivadeneyra, Madrid, 1854, pág. 494). Esta redondilla es glosa particular del estribillo, que funciona como letra ajena, sin serlo. Quizá el agente de la pasiva esté sugerido en la aliteración de sibilantes de los dos primeros versos.

${ }^{82}$ Cancionero Musical de Palacio, no 267. Frente a la activa Fortuna, él prefiere ocultar a estos otros en la pasiva («están escritos»), lo que denota algún tipo de verdad fuera del mundo expresado en los versos.

${ }^{83}$ A. Alciato, Emblemas (ed. de S. Sebastián), CXVIII, Akal, Madrid, 1993, pág. 156.

${ }^{84}$ Loc. cit., emblema XCVIII, pág. 132. Véase la interesante glosa de Bernardino Daza Pinciano a este lema (Los emblemas de Alciato traducidos en rimas españolas [Guilielmo Rovillio, Lyon, 1549]; ed. de R. Zafra, J. J. de Olañeta/UIB, 2003, pág. 234).

${ }^{85}$ Virgilio, Eneida, X, 28.

86 «Vida mayor» de don Luis (recogida en Foulché-Delbosc, op. cit., III, pág. 297; la cursiva es mía). La queja de los amigos es constante. En la Vida i escritos de don Luis de Góngora (Preliminares del ms. Chacón), don Antonio revela: «El estado, dignidades, i comodidades de Don Luis, si no fuera vano nombre el de la Fortuna, muy corrida la dexàran de la vengança que quiso tomar de la naturaleza, en la singularidad d'ste estraño, i diuino Genio: pues vn cauallero de tantas parte, ni en menores, ni en maiores años pudo ascender de un Racion de la Santa Iglesia de Cordoua, gloria de su Iglesia, de su patria, de sus meritos no auerle mirado 
Es la voz resignada del racionero la que se escucha en el segundo verso, el del coro. La otra voz, la del poeta, es más libre, y se encamina a la entrada de la orchestra con el tono burlesco y desenfadado de las artes de la parodia ${ }^{87}$. A diferencia de la «letrilla de la fatiga», es el espacio escénico - no las palabras - lo que se vuelve, y necesita otro espacio libre en que recalar. Allí, entre el público que escucha sentado en las gradas levantadas en el mundo extensional y el proscenio donde se erige Fortuna, se abre la orchestra, no ya con la flauta y la cítara que acompañan el canto dolido del macho cabrío ${ }^{88}$, sino con los «pitos» $\mathrm{y}$ «flautas» burlescos del ditirambo gongorino ${ }^{89}$.

«Quem virum aut heroa lyra vel acri / tibis sumis celebrare, Clio?», demanda Horacio a la musa de la Historia ${ }^{90}$. Don Luis no suscribe la imprecación en un primer nivel. Apartada la lira heroica, asume la ironía de que los labios de Clío sirvan de fuelle al acre, una flauta que en sus manos puede registrar los distintos agudos de la flauta y del pito ${ }^{91}$. En este momento surge la duda. Si las palabras que no pronuncian los labios de Clío tampoco las articula Fortuna, al esquema propuesto - válido para la lectura sentencial, burlescamente argumentativa- le falta algo. Las palabras que designan los instrumentos no están mencionadas, no se habla de los pitos ni de las flautas, sino de males y «bienes» que «están escritos» (no se sabe por quién), y de «bienes» y males que Fortuna imparte aleatoriamente. Una fórmula que puede aclarar el fenómeno podría ser:

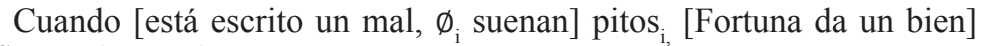
flautas (suenan).

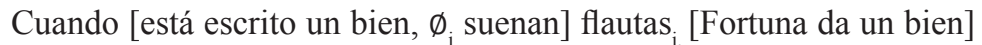
pitos (suenan).

templadamente, cuanto mas reidose con el de la Fortuna. Que ingenio, empero, tal viuio sin algunas lagrimas?».

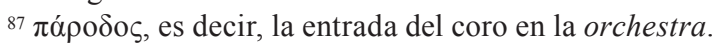

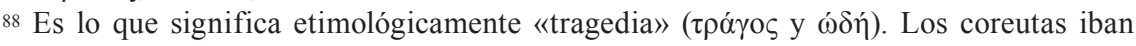
disfrazados de este animal tan cercano a Dionisos.

${ }^{89}$ El maestro Pedro González de Sepúlveda ofrece una explicación poco habitual pero muy conveniente: «La ditirambo, en fin, era poesía que imitaba a un mismo tiempo con palabras, música y baile. De este género, pues, de imitaciones vemos tan llenos hoy los teatros [...]; por donde me persuado que nunca más válida que ahora se ha visto la ditirámbica» (en F. de Cascales, Cartas filológicas, Luis Verós, Murcia, 1634, déc. 3a, ep. IX). Hay cierta liturgia de la palabra poética escenificada bajo los modos del sermo latino (cf. J. Lara Garrido, «La predicación barroca, espectáculo denostado [textos y considerandos para su estudio)]», Analecta Malacitana, VI, 1983, págs. 381-387).

${ }_{90}$ Odas 1, 12. Unos versos antes (Odas 1, 10), Mercurio aparece jugando con el destino, primera imagen de los emblemas de Fortuna que se han descrito. Es muy posible que Góngora asumiese ambos pasajes en la factura de la letrilla.

${ }_{91}$ M. Querol Gavaldá intuye que «pito» es el nombre con que se conocía al pífano (o píffaro), «una flauta travesera muy aguda» que acompañó a los soldados suizos que lucharon en las guerras de Granada y más tarde siguieron al Gran Capitán en la campaña de Italia (La música en la obra de Cervantes, pág. 184). Cervantes describe su sonido: «A deshora se oyó el son tristísimo de un pífaro» (Quijote, II, XXXVI). Aquí no parece el «silbato infantil» del que habla Covarrubias (s. v. «pito»). 
Ahora la parte de la escena donde están las páginas con los distintos nombres de los bienes es el lugar donde se sitúan los instrumentos, en tanto, en el proscenio, Fortuna muestra el reparto, pero sin instrumentos que la acompañen. La voz del poeta se escuchaba en el segundo verso, espacio del coro, y organiza el conflicto extensional de manera binaria, jugando con la retórica del paralelismo especular y con la metáfora de los pitos y las flautas ${ }^{92}$ en ausencia de esos males y bienes que no se desea revelar. A pesar de ello, es otra figura, sin voz, quien, recogiendo la naturaleza sinestésica de la metáfora icónica, dirige el coro y permite la entrada $(\pi \alpha$ ó $0 \delta$ s) directa en la orchestra a cada uno de los instrumentos elegidos ${ }^{93}$, sin necesidad de tiples o bajetes.

Estas maneras miméticas están destinadas al lector u oyente que conoce cada uno de los espacios (proscenio, coro, orchestra) y tiempos (el primer momento del conflicto y la posterior entrada del coro) de la comedia antigua; un público consciente no tanto de las implicaciones expresadas en las palabras como del sentido final de la escena mostrada: la espacialidad de la grosera higa burlesca bajo la forma primitiva de los temporales y agudos pitos. Así, en Góngora tenemos «en unas mismas plumas escondido/el músico, la musa, el instrumento» ${ }^{94}$.

\section{3. «Ridentem dicere verum quid vetat?»95}

Los caprichos de Fortuna suelen desalentar a los poetas, aunque no todos responden igual. A Sebastián de Horozco, por ejemplo, le atrae la gallardía

92 Sobre esta letrilla, L. M. Vicente García advierte: «Por supuesto también usa Góngora imágenes musicales en su vena satírica. A veces en metáforas lexicalizadas convertidos en dichos populares ajenos al significado original de los instrumentos» («Notas sobre la imaginería musical y el amor en la poesía de Góngora», Edad de Oro, XXII, 2003, 205-219, pág. 219).

${ }^{93}$ No son pocos. «En mi aposento otras veces/una guitarrilla tomo,/que como barbero templo y como bárbaro toco» (no. 83, de 1590). La guitarrilla también se escucha en la plaza «mucho, después de la queda» (letrilla VII, de 1581). En el romance «Hermana Marica» suenan «el adufe» y «las castañetas». Su credo vital se consigna «Escuchando a Filomena/bajo el chopo de la fuente» (letrilla XXIV, de 1581) y no muda en los años siguientes: "Ahora que estoy despacio, / cantar quiero en mi bandurria» (n. 73, de 1588), o en esa «vihuela» que es «potro de dar tormento» (letrilla XIV, de 1595). En el romance "Cuando la rosada Aurora» (no 152, de 1603), aparecen «cerdas», «rabelillos», «viento», «organillo», «trompa», «zampoña», «violón», «letra», «canción», «varejón», «fuga», «compás», «proporción», «voz». Más inesperadas son las «roncas bocinas» del estribillo de la canción «De un monte...» (no 147, de 1609). En los tercetos «iMal haya en que en señores idolatra...!» (n. 202) convoca a su «república volante» a «tiplones» y «bajetes mermelados» para que «Pájaros suplan, pues, faltas de gentes, / que en voces, si no métricas, süaves, / consonancias desaten diferentes» (vv. 19-21) No podían faltar las «tïorbas» (347, v. 35) ni el canto «al son de un laúd con ramas» (no 35, v. 19). Más tarde afloran «cítara», «cuerdas», «instrumento», «trastes», «órgano» (no. 384, de 1622), «que muestran cuán erudito era Góngora en materia musical» (M. Querol Gavaldá, Cancionero Musical de Góngora, CSIC, Barcelona, 1975, pág. 20). Sorprende que este autor no haga referencia a las «flautas» y los «pitos» de nuestro estribillo.

${ }_{94}$ Tercetos «iMal haya en que en señores idolatra...!» (no 202, vv. 29-30).

${ }^{95}$ Horacio, Sátiras, ed. bilingüe de H. Silvestre, I, 1, 24, Cátedra, Madrid, 1996. 
que denota la copla ajena «Bien puede Fortuna esquiva/por más que pensado quede, / quitarme tierra do viva, / mas, do muera, no puede», pero su glosa le quita hierro al asunto:

$$
\begin{aligned}
& \text { Es posible y suele ser } \\
& \text { porque Fortuna les hierra, } \\
& \text { muchos hombres no poder } \\
& \text { en este mundo tener } \\
& \text { por suyo un palmo de tierra }{ }^{96} \text {. }
\end{aligned}
$$

Todo es cuestión de probabilidades, y así lo recogen los cabos léxicos de la glosa de Horozco («Es posible y suele ser», «no poder») y de la copla («Bien puede [...], no puede»). Esta copla ajena posee el vigoroso carácter icónico que se despliega en el diseño retórico de la letrilla vivencial «de Fortuna». El paso siguiente (o anterior, tanto da) ${ }^{97}$ es hacia la plaza pública, y Góngora ajusta el lugar y el talante:

$$
\begin{aligned}
& \text { Que pida a un galán Minguilla } \\
& \text { cinco puntos de jervilla, } \\
& \text { bien puede ser; } \\
& \text { mas que calzando diez Menga, } \\
& \text { quiera que al justo le venga, } \\
& \text { no puede ser }{ }^{98} \text {. }
\end{aligned}
$$

El poeta no llega a ser músico e instrumento. Su lugar todavía no es el coro ni la orchestra, y el proscenio se llena de figuras, quizá por eso hay una voz que acompaña a cada uno de los actos que se muestran en la escena. Una voz que pide tácitamente licentia al público de la grada para que se adhiera a su causa porque lo considera «capaz de enfrentarse a una verdad objetiva desagradable»"99. Pero dicha voz está aún lejos del reproche valiente de «Manda Amor...» — donde defiende en un ambiente más reservado la derogación del tópico: «que yo pienso muy sin mengua/dar libertad a mi lengua,/y a sus leyes una higa» (21-24)—, lejos también de las intimidades en la apelación («Escuchadme un rato atentos, /cudiciosos noveleros/pagadme de estas verdades/los portes en el silencio») ${ }^{100}$ y todavía más lejos de la algarabía de la plaza pública:

Arrímense ya las veras y celébrense las burlas,

\footnotetext{
${ }^{96}$ S. de Horozco, Cancionero..., n. 337.

${ }^{97}$ Es posible que las letrillas VII y VIII se maduren en paralelo.

${ }^{98}$ Letrilla VII, del mismo año; vv. 1-6.

${ }^{99} \mathrm{H}$. Lausberg, Manual de retórica literaria, Gredos, Madrid, 1966-1969, § 761.

${ }^{100}$ № 59 , de 1585.
} 
pues da el mundo en niñerías, al fin, como quien caduca ${ }^{101}$.

El poeta es consciente de que un talante apropiado en que los modos de apelación ni siquiera se expresen produce en el lector emociones hondas más que pasiones fugaces ${ }^{102}$. Conseguida la licentia del auditorio, resultado de la madurez poética, ya puede ser insolente con sus vecinos, esos «arroyos» de su tierra que «Si corréis sordos, no quiero hablaros,/mejor es que corráis murmuradores, / que llevo muchas cosas que contaros ${ }^{103}$.

El amable, ético «Si sus mercedes me escuchan,/les contaré a sus mercedes» no llegará hasta $1590^{104}$, así que, por ahora, la proclamatio ${ }^{105}$ queda muy menguada en el quebrado. Es el momento de regresar a la autoridad de los mayores. En el cartapacio aparecen, entre otras, aquellas redondillas de pie quebrado donde don Diego expresaba su queja de amor ${ }^{106}$. El vigor icónico de sus relata (el yo y su predicado, la situación pasional aquí y así) en el modo alegórico, secundados por la intensidad creciente de los latidos de ese corazón (-ón) que dobla desbocado en la consonante de los cabos nominales que forman dicho modo, no lo dejan indiferente. Poco después — sub contraria especie pero con la misma voz - llega la asunción reflexiva, que encuentra acomodo en las maneras contenidas del quebrado emocional, verso del poeta militante - no verso «de autor»- cuyo temple (motivo primario) se justifica en la rima reversa y en el tiempo silábico sin dilación, conformes con los esquemas métricos dominantes.

Este patrón retórico se ajusta bien a la expresión de la secuencia patética porque anuda ambas labras del quehacer poético con el instrumental de los verba. La res, en cambio, es simple ratio adversativa que pretende referencialidad, de ahí el asalto del yo lírico a cualquier plaza que pueda acogerlo, en especial la flexión verbal. En esta disposición de la «razón de amor»que se alimenta de los hábitos petrarquistas hay un orden natural elaborado en

101 No. 73, de 1588 (vv. 5-8) y cuya primera cuarteta muestra el ethos gongorino en este momento: «Ahora que estoy despacio/cantar quiero en mi bandurria,/lo que en más grave instrumento/ cantara, mas no me escuchan».

102 Los ingredientes emocionales de la persuasión afectan al lector, que también anticipa los suyos ante el poema. La argumentación retórica debe diferenciar bien el ethos (del poeta) y los éthe, los factores emocionales del auditorio (cf. Aristóteles, Retórica, ed. cit., 1356a13-15 y 1377b15-78a29; también la Introducción de Quintín Racionero, págs. 98-99 y 108-11).

103 « Mal haya en que en señores idolatra...!», de 1609 (no. 202, vv. 7-10).

104 «no las hazañas del Cid/ni de Zaida los desdenes, / sino más de cuatro cosas / que se yo que se comenten/o se dejan de hacer/por el decir de las gentes» (romance con estribillo no 84 , vv. 3-8).

105 Esto es, una «apóstrofe con ruego» (F. Sánchez de las Brozas, Ars dicendi, en E. Sánchez Salor y C. Chaparro Gómez, eds., Obras I. Escritos retóricos, Institución Cultural «El Brocense», Diputación Provincial de Cáceres, 1984, § 114).

106 «Estoy en una prisión,/en un fuego y confusión/sin pensallo,/que aunque me sobra razón/para decir mi pasión,/sufro y callo». Véase la nota 5. 
torno al contrapunto entre los miembros creciente y decreciente ${ }^{107}$ del dístico y a su radical monofonía. Es la convergencia funcional de sus miembros lo que provee de musculatura a la redondilla, modelando el indiviso: un cuerpo consonante cuyo corazón late con fuerza (-ón/-ón) y bombea la sangre que extrema la pasión (ley natural de los miembros crecientes), y una estimativa que reflexiona en la poquedad del miembro decreciente.

La letrilla de Góngora, por su parte, recoge sub especie similis el contrapunto icónico de la redondilla, pero sub especie contraria apuesta por lo diverso. La naturaleza de la proclamatio jocoseria no puede prescindir de la polifonía, único modo en que el asunto ${ }^{108}$ amoldado en el dístico y el yo burlesco reducido en el quebrado puedan disfrutar de dominios reservados. Son las exigencias del cambio de paradigma, ahora construido en torno a la proyección del yo burlesco registrada en esa rima aguda («bien puede sēr»/ «no puede sēr») ${ }^{109}$ que denota, en su cantidad ${ }^{110}$, la aceptación irónica o la simulada indignación. Sea como fuere, para el ajuste del quebrado hay que acreditar un argumento de paso que respete el ordo naturalis y la polifonía, aunque sea en ciernes. La autoridad avala una vez más a don Diego:

\author{
El decir que le salieron \\ las canas en la niñez \\ y que de golpe otra vez \\ los dientes se le cayeron, \\ $\mathrm{y}$ atestiguar que lo vieron \\ quien en tal no pudo hallarse, \\ no puede tragarse.
}

${ }^{107} \mathrm{La}$ «ley de los miembros crecientes» — recurso con solera en la literatura indoeuropea - exige una ajustada desproporción en la intensidad emocional de los diversos miem-

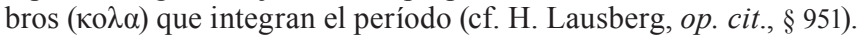

${ }^{108}$ El sujeto (subiectus).

${ }^{109}$ Esta estrofa de versos quebrados agudos que rematan los pareados monorrimos (aa $b: a a b$ ) se denomina «sextilla simétrica». De origen provenzal, aparece ya en los segundos Gozos de Santa María: «Virgen, del çielo reína,/e del mundo melezina,/quiérasme oír, /que de tus gozos aína/escriva yo prosa dina/por te servir» (Libro de Buen Amor, vv. 1-6). Por su parte, las redondillas de Hurtado de Mendoza, con pareados de rima aguda y quebrado de rima llana, son antístrofa de la sextilla y, como tal, dignas de un estudio particular. Por último, los versos irregulares de la glosa o mudanza de algún villancico del Cancionero Musical de Palacio aparecen gráficamente dispuestos ya en cuartetas de rima alterna distinguiendo las prótasis de las apódosis, ya redimensionados en el período, con la forma de un dístico monorrimo. Valga como ejemplo del primer caso: «Por bever, comadre,/por bever/Por mal vi, comadre/tu vino pardillo,/que allá me tenías/mi saya y mantillo./Por bever» (no. 235). Véase M. Frenk, Nuevo corpus de la antigua lírica popular hispánica, FCE/El Colegio de México, México, 2003, no. 1586.

${ }^{110} \mathrm{La}$ aparente hipermetría cuestiona la voluntad de estilo del poeta. El ardid de que la aguda cuente como un solo tiempo en la escansión del verso («Ley de Mussafia») resuelve el asunto, pero anula la fuerza patética del verso como refrán. Por otra parte, «La forma más breve de este orden ascendente consiste en la simple posición final del miembro más fuerte» (H. Lausberg, op. cit., § 451). 
El modelo de esta carta a una dama vieja — que glosa la letra «Ser vieja y arrebolarse/no puede tragarse»-111 cumple con creces las expectativas: acomoda las voces de la vieja y de los vecinos en el cuerpo de la copla y se reserva el estribillo-predicado para la voz deliberativa de su indignación. Esto último no es nuevo en los cancioneros, pero la escena descrita en la copla goza de una compositio que debe su sencillez a un cuidadoso ordo naturalis. Su figura podría tener el siguiente aspecto:

El «decir que... \& atestiguar que...» no puede tragarse.

A la izquierda, el articulador extensional de la escena enclavada, a la derecha, el predicado intensional ${ }^{112}$, y, en medio, los dos actos de habla disjuntos que Hurtado de Mendoza conecta con la copulativa ${ }^{113}$. La escena es burlesca por la paradoja creada por la conectiva, no por las solas palabras de la vieja, que no merecen ningún tipo de predicado, en especial el burlesco «bien puede ser». El alcance corto de la conectiva es la cota de burla a que puede aspirar el diseño de la copla. Esta perspectiva de mundo único se convierte en mundo posible en el caso de Góngora, en el mundo de veras y burlas (en este orden) constituido en torno al alcance más largo de la conectiva:

\& «Que pida... bien puede ser», «que calzando... no puede ser».

Así, con un simple giro léxico —ese modesto «mas»— que obliga a la predicación doble, los posibles modelos del villancico de don Diego se ofrecen para que Góngora inicie sus pasos satíricos en el modo del género formal de «veras y burlas» ${ }^{114}$ que bebe en lo agrio de la sátira nueva ${ }^{115}$. Agradecido, rinde tributo al maestro:

Que anochezca cano el viejo, y que amanezca bermejo, bien puede ser;

${ }^{111}$ № CXXXIX. En el Cancionero sevillano de Nueva York aparece en la forma «Ser vieja y arrebolarse/ es dura cosa tragarse» (ed. de M. Frenk, J. J. Labrador Herraiz y R. A. DiFranco, Universidad de Sevilla, 1996, no 443). Aquí no es tan claro el contrapunto de burlas y veras que sí aparece en cada una de las coplas de la edición de Hidalgo (Juan de la Cuesta, Madrid, 1610, fol. 149 y v.).

112 Es un predicado de creencia y, por lo tanto, afecta a la interpretación del contenido proposicional de la glosa.

113 Valga «\&» como símbolo del conector copulativo. Las comillas señalan la proyección máxima de la escena secuencial.

${ }^{114}$ En su Alfabeto tercero, denominado por el autor La razón de algunos refranes (ed. de B. Russell Thompson, Támesis, Londres, 1975), el doctor Francisco del Rosal, nacido hacia 1560 y paisano de Góngora, incluye «Burlas y veras» como refrán que proviene «Del adagio latino Joca seriaque» (pág. 28). Erasmo lo incluye en sus Adagia (no. 1024) con la autoridad de Cicerón (De finibus, II).

${ }^{115}$ La sátira nueva o «latina» revela los defectos de los individuos (las mujeres, los homosexuales, etc.) o de la sociedad (la avaricia, la pereza o la cobardía...). 
mas que a creer nos estreche que es milagro y no escabeche, no puede ser ${ }^{116}$.

Evidentemente el cumplido acaba en el icono, pues la intensidad emocional del estribillo no se ajusta al talante del joven Góngora, cuyas veras y burlas no parecen mordaces sencillamente porque desde lo hondo de la máscara repercute (é-e-é/ó-e-é) el eiron. Hay algún secreto intencional en la voluntad de estilo de Góngora que cuadra mal con la copla binaria, quizá por eso su voz se aleja de la escena de «vera-burla» como se aleja el enamorado que quiere bien a la dama: "pero no os oso mirar/por mil lenguas que ay parleras»"17. Causas inversas para asuntos poéticos desiguales, pero una misma actitud. Todavía no está preparado para recibir «cuando verdades no diga,/una higa» ${ }^{118}$, y se enmascara antes de acceder a la plaza pública. Vestir la voz de magodo ${ }^{119}$, de «lengua parlera», aleja el discurso grave ${ }^{120} \mathrm{y}$ lo acerca al espectador:

Que en la cosas que hazemos se noten malos estremos, bien puede ser; mas que las parleras lenguas callen donde vieren menguas no puede ser.

La estrofa sólo aparece en un valioso manuscrito ${ }^{121}$, pero es la evidencia de que la propuesta burlesca de Góngora está expresada desde el principio. Las 21 estrofas de la letrilla no se diseminan para que el oyente, por inductio, rinda cuentas de sus frutos, son glosa de una letra y es a posteriori cuando actúan de exemplum. Sólo así se entiende la existencia de esta estrofa. Por otra parte, si las 21 coplas se ajustan demostrativamente - como catálogo de individuos- a la cabeza, es posible que esta letra se ajuste, a su vez, a su reductio bipartita de veras y burlas.

116 Vv. 25-30. La cuarta estrofa del villancico de Hurtado y la quinta de la letrilla gongorina son ejemplos de un «tipo» común en lo poético, no sólo en lo retórico.

117 Cancionero de Pedro de Rojas (1582), ms. 3924, BNM, ed. de J. J. Labrador Herraiz, R. A. DiFranco y M. T. Cacho, Cleveland State University, 1988, no. 63. También en el Cancionero de poesías varias. Ms. $1587 \ldots$, n. $^{\circ} 290$.

118 Letrilla XII, de 1593, vv. 6-7.

119 en sus Dipnosofistas, Ateneo de Naucratis, siguiendo a Aristoxeno, asegura que una variedad del mimo era el «magodo» (o «magodia») que representaba personajes de ambos sexos con atuendos de mujer (cf. El banquete de los eruditos, trad. de L. Rodríguez-Noriega Guillén, Gredos, Madrid, 1996-2014, 5 vols., 620E.

120 «Entre lo demás que era/necesario en la mujer,/callar y no ser parlera,/porque es de otra manera/digna de reprender. / La buena mujer debría/dar la palabras por peso,/pues cuando en hablar porfía, / lo que sobra en parlería/es lo que falta en el seso» (Cancionero de Sebastián de Horozco, n. 305).

${ }^{121}$ Aparece en cabeza de la letrilla en el Cancionero de Gabriel de Peralta (ms. 4072, BNM, fol. 65). R. Jammes, en su edición crítica de las letrillas, la denomina «a» (1963, pág. 36). 
En un refrán atestiguado ya en Vallés ${ }^{122}$ («Ser puta y buena muger/ ¿cómo puede ser, señor bachiller?»), la requesta paradójica en torno al modo se autoriza en el grado. La respuesta del oyente como bachiller zozobra entre el deductivamente satírico «no puede ser» o el inductivamente redentor «bien puede ser», pero en ambos la respuesta es la parte de la glosa implicada en el diálogo. Pedro de Padilla toma el testigo y ofrece el modelo en toda su extensión:

¿Que no puede ser, señor liçençiado!

¿Que sí puede ser, señor bachiller!

Si dezís que amor es ciego, ¿cómo tira sin errar o cómo save aplicar con diferençia su fuego?

¿Que no puede ser, señor liçençiado! ¡Que sí puede ser, señor bachiller!'123

La letrilla gongorina puede originarse en «estribillos de debate» como este del Romancero de Pedro de Padilla, que emplea la autoridad del refrán para forjar un diálogo que designa «en el grado» a sus milites carminis amatorii. Así, vuelta la paradoja a lo cancioneril, se restablece la capilla de los elegidos. Entre las aficiones poéticas de Góngora no se encuentran todavía la pregunta medieval o las cartas de los cancioneros quinientistas. Las quaestiones finitas ${ }^{124}$ denotan causas poéticas que implican de un modo u otro al autor, y él no está aún en tales impulsos, por lo que el acertijo y el debate posterior se derogan en un cuidado diseño de «mundo de veras y burlas». Góngora no necesita suscribir el motivo del estribillo de Padilla, le basta asumir (casi imitar) el icono evidenciado en él, más hondo que el forzado diálogo, con el que sí comparte el retraso de la escena a los lugares de la glosa.

Sólo aparentemente. La cancelación del diálogo original lleva de suyo la supresión del vocativo, y con él la capilla de los milites. Pero también exige la desaparición del estribillo como letra del villancico. Aunque no hay fuente que lo acredite, la letrilla puede haber corrido en pliego con el estribillo

122 Libro de refranes y sentencias de mosén Pedro Vallés, Zaragoza, Juana Milián, 1549, fol. 67v. También en los Refranes o proverbios en romance..., de Hernán Núñez (Juan de Canova, Salamanca, 1555, fol. 117v) y en El libro de los proverbios glosados (1570-1580) de Sebastián de Horozco (ed. de J. Weiner, Reichenberger, Kassel, 1994, no. 2798).

${ }^{123}$ Romancero, Sociedad de Bibliófilos Españoles, Madrid, 1880, pág. 521. En el Cancionero de poesías varias. Ms. 1587 (códice que parece ser, según explican sus editores en la pág. XXX, de 1588), se reconoce como «Letra de Padilla» porque cabeza y glosa son de la misma pluma (pág. 285).

124 Véase H. Lausberg, op. cit., §§ 68-69. 
reducido a mote ( «Bien puede ser; No puede ser») $)^{125}$, es decir, como glosa del mote ${ }^{126}$, conjetura que tiene en su contra el celebrado enigma del refrán y la innegable popularidad de Pedro de Padilla. Apoderando el paso del refrán de lo popular a lo cancioneril, ambas autoridades clausuran la función «mote» del estribillo gongorino, al que sólo le queda resguardarse en los resquicios funcionales de la sententia, «una verdad sublime, recóndita, y prudente» en palabras de Gracián ${ }^{127}$.

Es cierto que el concepto de «verdad» parece trivial cuando se trata de burlas y veras. Se entiende mejor cuando la textura poética es sensible a ciertas condiciones del mundo del autor, es decir, resulta verosímil. Algo así ocurre con el villancico de Hurtado de Mendoza, donde los «latidos-rima» (-ón,-ón) son ostensión de la cárcel de Amor confinada en los dísticos. Pero Góngora no se encuentra en el momento de lo «ficcional-verosímil» sino en el de las verdades del racionero, «lengua parlera» que nos incluye en la misma situación espacio-temporal a todos: "Que en las cosas que en hazemos $^{128} /$ se noten malos estremos». De hecho, expresa esta verdad del racionero en modo burlesco, mediante un «predicado de vera» con textura alojado en el estribillo, y con el que el poeta sentencia la escena con ethos indulgente desde dentro de la comunidad burlesca $^{129}$.

${ }^{125}$ Entre las muchas cosas que Góngora le debe a Horacio se encuentra esta perspectiva estoica de moral pública enraizada en un epicureísmo de moral privada que alcanza a veces la diatriba moral de los filósofos cínicos, género que trata de manera popular, incluso vulgar, temas graves. La instrucción «Fuera de no, sí, cállate» ya aparece en hexámetros horacianos: «ultra/non, etiam sileas» (Sátiras, 2, 5, 90-91). Más tarde la Vulgata la propaga a Occidente: «Sit autem sermo vester, est, est, non, non» (Mateo, 2, 37). La fórmula adquiere los perfiles del mote en el Cancionero general de obras nuevas: «No, no; sí, sí. / El no, no. El sí, por sí. / No sé quál d'ellos m'escoja/porqu'el no no es para mí» (Esteban de Nágera, Zaragoza, 1554, ed. de C. Clavería, Delstre's, Barcelona, 1993, no. 58). No obstante, el patrón ya está anticuado en tiempos de Góngora, como corrobora Jáuregui en el Antídoto: «el sí y el no de que estamos todos tan cansados y ahítos» (E. J. Gates, Documentos gongorinos. Los discursos apologéticos de Pedro Díaz de Rivas. El antídoto de Juan de Jáuregui, El Colegio de México, 1960, pág. 111). Cf. el capítulo de Otis H. Green dedicado al «Sic et non» (España y la tradición occidental. El espíritu castellano en la literatura desde «El Cid» hasta Calderón, I, Gredos, Madrid, 1969, págs. 19-43, 4 vols.).

126 «Texto de un sólo verso que sirve de cabeza a una glosa» (J. Domínguez Caparrós, Diccionario de métrica española, Alianza, 1999, s. v).

127 «Pero las que son propias desta Arte de Agudeza, son aquellas, que se sacan de la ocasión, y les da pie alguna circunstancia especial: de modo que no son sentencias generales, sino muy especiales, glosando alguna rara contingencia por ellas» (Agudeza..., disc. XXIX). La cursiva es mía.

${ }_{128}$ Es otra forma de hacer relativas (con el mundo del racionero) las proposiciones poéticas: someterlas a una explicatura locativa para que puedan señalar algún tipo de verdad extensional. Para la aplicación en la letrilla VII de estos segmentos «en $\ell$ », véase mi artículo «La geografía burlesca de Góngora...», págs. 89-99.

129 El predicado de verdad necesaria (extensional) que aparecía implícito en las dos letrillas anteriores encuentra ahora su expresión burlesca en un predicado explícito de verdad que denomino «de vera» («bien puede ser»). En esta estrofa, la proposición-sujeto muestra los distintos niveles de su iconicidad con las comillas, e incluye el «predicado de verdad» como parte 
Conseguida la autoridad por medio del argumento ético (no hay higa para ninguno de nosotros), sólo resta emplearla en situaciones en las que el racionero no se siente concernido, pero sí su yo parlero, disimulado entre «las parleras lenguas» - falsa modestia- cuyo norte es no callar «donde ${ }^{130}$ vieren menguas».

Las distintas instancias de la voz poética son estrofa y antístrofa sentenciadas con decoro en el epodo ${ }^{131}$. El modelo tripartito de la oda horaciana, asentada en la recusatio del tipo «alii-ego», se asume para la forja del mundo de veras y burlas, pero no en esta primera copla, que se inscribe más bien en la retractatio de asuntos graves («malos estremos») que no le mueven en estos momentos. $\mathrm{Si}$ esta estrofa hubiese corrido largo tiempo en pliego suelto, seguramente la edición de la letrilla tendría hoy el siguiente aspecto, con la estrofa (a) de cabeza y la actual (17) de primera estrofa' ${ }^{132}$ de la inductio:

Que en la cosas que hazemos se noten malos estremos, bien puede ser; mas que las parleras lenguas callen donde vieren menguas no puede ser.
Que se emplee el que es discreto en hacer un buen soneto, bien puede ser; mas que un menguado no sea el que en hacer dos se emplea, no puede ser.

En la consonancia de los dísticos monorrimos se muestra el rasgo de iconicidad ya apuntado en el villancico de Hurtado de Mendoza. Allí el corazón doblaba desbocado (-ón, -ón), pero los propósitos del cordobés se dirigen más bien a ligar la comunidad burlesca (estrofa $a$ ) con su voz poética (estrofa 17), que asegura que sí sabe «hacer un buen soneto», de ahí que ambas coplas se asemejen tanto en la rima.

Por otra parte, la escena presentada en los dísticos de la letrilla es muy esquemática. La acción se reduce a sus elementos básicos para el usufructo de un espacio métrico muy breve, pero ocurre que suele haber algo más que le provee de encarnadura y que no cabe en el esqueleto proposicional que descansa en el verso. Algunas veces se trata del contenido semántico, ampliado hasta lo imposible ${ }^{133}$, y otras es el fuelle de la rima el que sugiere un «caso burlesco». En ciertas estrofas, el poeta flexiona cada uno de sus dísticos - la escena completa - para ajustarse a las distintas formas del género de veras y burlas:

de lo expresado en el dístico, lo que permite a este adquirir la figura del mismo (y recurrente) «nombre icónico» que ya aparece en la letrilla «de la fatiga». La figura queda así: «"Que "en las cosas que hazemos/se noten malos estremos (es verdadero)"/bien puede ser».

${ }^{130} \mathrm{El}$ argumento locativo «donde» articula una escena sujeta al predicado de verdad donde el racionero (y no sólo el poeta) se encuentra cómodo.

131 «Decoro», lo aptum para cada parte. Epodo es el verso corto al final de una oda.

132 En «La geografía burlesca de Góngora...» estudio el adelanto de la estrofa 17 a los primeros lugares de la letrilla (págs. 91-93 y 128-131).

133 Para un análisis del usufructo del espacio métrico en estos dísticos, véase «La geografía burlesca de Góngora...», passim. 
la «vera», la «burla en forma de vera» o la «vera en forma de burla»134. La función de este «caso burlesco» ${ }^{135}$ va más allá del instrumental sonoro; se acerca al «latido-rima» del villancico de Mendoza pero vuelto a lo burlesco, como «latido-burla». Es el primer paso, callado, en el arraigo de la higa burlesca mediante la retórica del neuma ${ }^{136}$ que culminará en la letrilla «de la fatiga».

\title{
4. «Otro mundo es el mío, otro lugar»137
}

Es cierto que la estrofa (a) está condenada de antemano. La recusatio de asuntos que no está preparado para tratar es más propia del sermón satírico, o incluso de la oda horaciana, que de una composición en metro corto. Pero su deficiente recepción se debe, sobre todo, al logos adoptado para persuadir al lector, que cancela la necesaria confusión entre la vera y la burla. Además, el empleo del entimema retórico, de carácter deductivo, no es la mejor elección en estos primeros momentos; lo confirma la ruina de esta estrofa (a) y el consecuente traslado de la 17. Es el autor tan consciente de ello que, a pesar del éxito posterior del modelo ${ }^{138}$, no lo vuelve a emplear.

Pero la recusatio es innegociable. No se entiende la poesía burlesca del joven Góngora sin sus inseguridades frente a un mundo burlesco todavía forastero. En su letrilla XXIV, también de 1581:

\author{
Andeme yo caliente \\ y ríase la gente \\ Traten otros del gobierno \\ del mundo y sus monarquías, \\ mientras gobiernan mis días \\ mantequillas y pan tierno,
}

134 Depende de cada estrofa. Fray Juan de Pineda asegura «que ay burlas de veras, y veras de burlas, y veras de veras, y burlas de burlas, y esta quarta manera no se permite a los varones graues, y las demas si» (Primera parte de los treynta y cinco dialogos familiares de la Agricultura christiana, Pedro de Adurça y Diego Lopez, Salamanca, 1589, III, § 4, pág. 60).

135 Se aprecia mejor en la estrofa de Minguilla (véase supra) donde la rima opone el caso en -illa (de la joven) al caso en -enga, la respuesta con voz poética ayudada de cierta gestualidad (el comienzo de la actio elocutiva) a las pretensiones imposibles de la vieja Menga.

136 «es quando por una voz casi inarticulada y no perfecta declaramos algún extremo de grande alegría o pesar [...]. En el Latino se verán otros exemplos a quien corresponden los silvos y relinchos que se suelen dar» (B. Jiménez Patón, Elocuencia Española en arte (1604), cap. XII, El Crotalón, Madrid, 1988). «Figura Rhetórica, con que mas por señas exteriores que por voces, se expresa la interior voluntad» (Aut., s. v).

${ }_{137}$ Diego Hurtado de Mendoza, Epístola a don Luis de Ávila (XII, v. 154).

138 Véanse D. Alonso (Obras completas VII. Góngora y el gongorismo, Madrid, Gredos, 1984, págs. 346-351) y A. Alatorre, «La popularidad de una letrilla de Góngora», Anuario de Letras, XXIX, 1991, 17-40, pág. 23 y sigs. 
y las mañanas de invierno naranjada y agua ardiente, y ríase la gente ${ }^{139}$

acude, al igual que en la letrilla anterior, a la autoridad del refrán antiguo ${ }^{140}$, que en esta ocasión es tan descriptivo que parece solicitar únicamente su asunción. De hecho, el estribillo aparece como entimema de la recusatio ${ }^{141}$ del tipo «aliiego» que está empleando (o ha empleado no hace mucho) en la estrofa (a) de la letrilla anterior. Todo está dispuesto para el aplauso, que es el ánimo que le llevó no hace tanto a incluir este refrán en su codice excerptorii, junto a la letra de Padilla y las Cartas de Hurtado de Mendoza. Y así lo hace. Asume la «historia de la rebeldía» como reflexión existencial ${ }^{142}$ en el modo burlesco que propone la sintaxis del «estribillo-mote». Este recoge en su primer miembro tanto el segmento «en $\ell$ » del locus amoenus como el beatus ille horaciano

139 Primera estrofa. «Pequeño cuadro de contentamiento burgués un tanto cínico; pero que, siendo burgués, era popular para aquel tiempo» (A. Reyes, Obras completas, VII, México, FCE, 1958, pág. 207). Véanse también J. Guillén (Notas para una edición comentada de Góngora, Fundación Jorge Guillén/Universidad de Castilla la Mancha, 2002, págs. 45-47) y R. Jammes (La obra poética..., págs. 152-3).

140 Aparece como «Vaya yo caliente: y ría se la gente» en los Refranes famosíssimos y provechosos glosados (Burgos, 1509, ed. facsímil de M. García Moreno, Madrid, 1923, ix) que, según Eleanor S. O'Kane, parecen «haber sido impresos ya en 1490» (Refranes y frases proverbiales españolas de la Edad Media, Anejo II del Boletín de la RAE, Madrid, 1959, pág. 17). En una lista de refranes del Dr. Espinosa (denominada “D” por E. O'Kane) aparece este proverbio en la forma «Andeme yo caliente, rríase la gente» (ms. 10392, BNM, 10v. Hay una compilación moderna de la misma editora: Refranero de Francisco de Espinosa (1527-1547), Anejo XVIII del Boletín de la $R A E$, Madrid, 1968). Aparece con idéntica forma en Vallés (1549) y, en forma muy parecida, en los extensos refraneros quinientistas de Hernán Núñez (1555), Horozco (anterior a 1568) y Juan de Mal Lara (1568). La primera colección renacentista de importancia en que aparece puede ser el mencionado Refranero de Espinosa.

${ }^{141}$ Horacio lo expresa con suma claridad en la Epistola a los Pisones: «Vosotros, escritores, escoged materia a la altura de vuestras fuerzas y sopesad qué rehúsan, con qué pueden vuestro hombros. Al que elija un asunto a su medida ni la facundia le abandonará ni un orden brillante» (Arte poética, ed. de H. Silvestre, Cátedra, Madrid, 1996, vv. 38-41). Esta figura pragmática bipartita consiste en el rechazo de asuntos o géneros para los que el poeta no se siente capacitado. En cambio, prefiere dedicarse a otros más humildes, conformes a su competencia. La justificación apela al precepto del decorum para evitar el vicio de la desproporción. Obviamente, tratando de burlas y veras la táctica se vuelve a lo jocoserio.

142 «Podría considerarse como expresión de una manera de ver el mundo, de una postura vital [...]. Postura que cabría resumir en el famoso estribillo de la letrilla gongorina» (A. Pérez Lasheras, Más a lo moderno [Sátira, burla y poesía en la época de Góngora], Anejos de Tropelías 1, Zaragoza, pág. 31). La sinceridad del estribillo se evidencia en que no aparece en el Origen y etymología de todos los vocablos originales de la lengua castellana (ms. 6929, BNM, copia del XVIII) del Doctor Francisco del Rosal, nacido hacia 1560 y paisano de Góngora. $\mathrm{Su}$ Alfabeto tercero (op. cit.) es una glosa filológica unas veces, personal otras, de los refranes más notables del momento. Y este no parece serlo. 
con el poeta como sujeto ( Andeme yo caliente $_{\text {en }}$ »), ambos expresados en el después ${ }^{143}$ de cada (amplificada) antístrofa.

Obviamente, la sintaxis del refrán autoriza este logos del estribillo, anzuelo del pathos burlesco (la risa incluida en la textura), pero el talante del poeta dispone el diseño retórico de la recusatio como vuelta. En efecto, una vez asumido el motivo de la «historia de la rebeldía» inscrito en el estribillo, suscribe la concesiva «alii-ego» de la «historia de la resignación»144 —no explícita en la sintaxis del estribillo- para expresarse en la glosa con la (nueva) autoridad del tópico «menosprecio de corte y alabanza de aldea» (eje del diseño de las cuatro primeras estrofas). Es el conflicto modal entre lo que desea el racionero (modo volitivo) y lo que no le está permitido (modo deóntico), pero también es el argumento de paso que autoriza la voz aparentemente paródica (pero sólo burlescamente mendaz) del poeta, que por vez primera eleva la voz ( «Sepan quantos...») para acallar, bajo el ala del mote, su conciencia de racionero.

Con todo, el empleo de la autoridad del refrán en el estribillo es fundamental en el camino de lo jocoserio de veras y burlas ${ }^{145}$ porque garantiza algunos métodos propios de la letrilla VII y los dispone adecuadamente para el diseño de las letrillas «de Fortuna» y «de la fatiga». La sistemática de veras/burlas no depende aquí de un predicado «de vera» constante (como en la letrilla «Que pida a un galán Minguilla») o de un predicado «de verdad» implícito, como en las letrillas «Da bienes Fortuna» y «Manda Amor en su fatiga». Estas dos vías de la «poética del estribillo» de Góngora se cruzan en esta letrilla xxıv, donde el primer miembro de cada uno de los períodos estróficos expresa ${ }^{146}$ una vivencia del racionero que puede ser predicada extensionalmente ${ }^{147}$ : «Coma en dorada vajilla/el príncipe mil cuidados, /como píldoras dorados (es verdadero)»148, en tanto que el segundo instaura su verdad poética mediante un predicado

143 J. Lara Garrido estima que «el dicho popular y las costumbres cotidianas dan una gracia insuperable a motivos no tratados en la tradición poética anterior» (Del Siglo de Oro [métodos y relecciones], Universidad Europea/CEES, 1997, pág. 193). En efecto, el estribillo es un ejemplo de la «agudeza compuesta»: como inscripción condensa ambos tópicos y como suscripción los vuelve propios.

${ }_{144}$ En la forma de la recusatio de la media del silogismo práctico, que propone una premisa de deseo que Góngora no es capaz de cumplir. Todo se inscribe en la tradición del refrán «Ande la rueda y coces con ella» que describe a los niños haciendo un círculo y pateando al que se queda fuera (véase M. Frenk, Nuevo corpus..., pág. 1559). La metáfora es aplicable a Góngora, de ahí: «Y ándese la gaita por el lugar» (letrilla XXXIV, v. 4), que se asemeja a «y ríase la gente» pero también anticipa la letrilla «de Fortuna».

${ }^{145}$ Según J. Ponce Cárdenas, con la Fábula de Píramo y Tisbe culmina «un proceso de renovación barroca, cuyo eje es la fusión de burlas y veras, cuestión vital para una poética revolucionaria que permitía a los textos ir más allá de los estrechos límites de la parodia» (Góngora..., op. cit., pág. 35).

146 Salvo las estrofas quinta y sexta, dedicadas a Leandro y su dama, y a Píramo y Tisbe (véase la nota anterior), que cierran poéticamente la letrilla.

${ }_{147}$ Mediante el consiguiente predicado «de verdad».

148 Segunda estrofa de la letrilla. 
«de vera» (semejante a «bien puede ser»/ «no puede ser») autorizado en la textura del segundo miembro del refrán ${ }^{149}$ :

\author{
que yo en mi pobre mesilla \\ quiero más una morcilla \\ que en el asador reviente,

$$
\text { y ríase la gente }{ }_{\text {(predicado «de vera en forma de burla») }} 150
$$

Y es que «no puede ser» de otra manera. Son las dos caras de la misma moneda: la faz del poeta y la cruz del racionero ${ }^{151}$. Es el segundo quien propone la recusatio y quien levanta por primera vez el dedo de la higa ${ }^{152}$, pero es el poeta el único autorizado para, de manera tácita, mostrarla burlescamente al resto del mundo: «y ríase la gente».

${ }^{149} \mathrm{Y}$, por lo tanto, intensionalizado.

150 Aquí, como en la letrilla VII, el poeta se encarga de asumir la escena con la textura de un predicado «de vera» autorizado en el refrán («bien puede ser» $\approx$ «y ríase la gente»).

${ }^{151}$ Sólo en una ocasión ambos flancos se sellan en el anverso del mundo del racionero. Las fechas marginales en Chacón (19 y 29 de agosto de 1623) de los sonetos «En este occidental, en este, ¡oh, Licio!» (n. 388) y «Menos solicitó veloz saeta» (n. 389) parecen propuestas por el autor: «Dos indicios apoyan ab initio esa hipótesis, que no es otra que ver en 19 y 29 de agosto de 1623 dos días decretorios del horóscopo genetlíaco en un año particularmente propicio a la fatalidad: aquel en que Góngora cumplía los 63 años de edad» (J. Lara Garrido, «Con un soneto de Góngora [Sentido y forma de la meditación neoestoica en el ciclo de senectute]», en AA.VV. (eds.), Humanismo y pervivencia del mundo clásico: homenaje al profesor Antonio Prieto, IV, 1, CSIC, Madrid, 2008, 55-72, pág. 64).

${ }^{152}$ En el ms. 570 de la BPM aparece, bajo el título «Letras y figuras» (fols. 156r-158v) un proyecto de empresa que se ajusta bien al icono bipartito que denomino «higa burlesca». Esta divisa poética toma la forma de un verso bimembre con dos hemistiquios no rimados. El primero describe la figura ausente y el segundo suscribe la causa eficiente o final de la descripción. Un ejemplo aplicable a la letrilla «de la fatiga» antes de la vuelta a lo burlesco sería: «Una figa y diga/para ti si me olbidares» o «Una figa para quien mal me fiere». Para la letrilla «de Fortuna» (según lo dicho en el apartado 2): «Una muerte y dos figas a cada lado/la suya y diga/porque me dexo en tal vida». En las letrillas VII y XXIV los estribillos brindan «Una sortija con cuatrofigas / escoja quien murmurase» (cf. Cancionero de Garci Sánchez de Badajoz, ed. de Julia Castillo, Editora Nacional 1980, n 109). Inmediatamente después (fol. 158r), aparece el apartado «Otras sin figuras», lo que vendría a confirmar la existencia del icono. 
